\title{
Outcome-Based (Engineering) Education (OBE): International Accreditation Practices
}

\section{Prof. Junaid Qadir, Information Technology University, Lahore, Pakistan}

Junaid Qadir is an Associate Professor at the Information Technology University (ITU)—Punjab, Lahore since December 2015, where he directs the ICTD; Human Development; Systems; Big Data Analytics; Networks (IHSAN) Research Lab. His primary research interests are in the areas of computer systems and networking, applied machine learning, using ICT for development (ICT4D); and engineering education. $\mathrm{He}$ is the author of more than 100 peer-reviewed research papers that have been published at various top conferences and journals. He currently serves as the Chairperson of the Electrical Engineering department at ITU. He was awarded the HEC Best University Teacher Award, the highest national teaching award in Pakistan, in 2012. He is a senior member of IEEE. He is an ACM Distinguished Speaker for a three-year term starting 2020 and an ACM Senior Member.

Dr. Aamir Shafi, National University of Computing and Emerging Sciences, Lahore, Pakistan.

Aamir Shafi is currently an Associate Professor in the Department of Computer Science at the National University of Computing and Emerging Sciences. Aamir did his bachelors in Software Engineering from NUST Pakistan in 2003 and PhD in Computer Science from University of Portsmouth, UK in 2006. Aamir was also a Visiting Scientist at MIT, USA in 2010-11 where he worked on the award-winning Cilk technolgy. Aamir's research interests include designing and implementing parallel software on high-end computing platforms. Aamir is an architect and the main developer of an MPI-like library called MPJ Express (http://mpjexpress.org).

\section{Prof. Ala Al-Fuqaha, Hamad Bin Khalifa University (HBKU)}

Ala Al-Fuqaha received Ph.D. degree in Computer Engineering and Networking from the University of Missouri-Kansas City, Kansas City. He is currently a professor at Hamad Bin Khalifa University (HBKU) and Western Michigan University. His research interests include the use of machine learning in general and deep learning in particular in support of the data-driven and self-driven management of large-scale deployments of IoT and smart city infrastructure and services, Wireless Vehicular Networks (VANETs), cooperation and spectrum access etiquette in cognitive radio networks, and management and planning of software defined networks (SDN). He is an ABET Program Evaluator (PEV) with the Computing Accreditation Commission (CAC). He served on many academic program design, review and planning efforts. He serves on editorial boards of multiple journals including IEEE Communications Letter and IEEE Network Magazine. He also served as chair, co-chair, and technical program committee member of multiple international conferences including IEEE VTC, IEEE Globecom, IEEE ICC, and IWCMC.

\section{Dr. Abd-Elhamid M. Taha, Alfaisal University}

Abd-Elhamid M. Taha is an Assistant Professor of Electrical Engineering At Alfaisal University. His research spans radio resource management, Internet of Things (IoT) services, and modeling in networked cyber-physical systems. Abd-Elhamid is a senior member of the IEEE, and a recipient of the Natural Sciences and Engineering Research Council (NSERC) Early Career Researcher Award as well as several awards at Alfaisal University for distinction in teaching and research.

\section{Prof. Kok Lim Alvin Yau, Sunway University}

KoK-Lim Alvin Yau received the B.Eng. degree (Hons.) in Electrical and Electronics Engineering from Universiti Teknologi Petronas, Malaysia, in 2005, the M.Sc. degree in Electrical Engineering from the National University of Singapore in 2007, and the Ph.D. degree in Network Engineering from the Victoria University of Wellington, New Zealand, in 2010. He is currently a Professor with the Department of Computing and Information Systems, Sunway University, Malaysia. He teaches Computing subjects and has received numerous University Excellence in Teaching Awards based on student evaluation surveys over the years since joining academia in 2011. He was nominated by the University to conduct outcome-based 
education (OBE) workshop. He manages the PhD in Computing programme and has been implementing OBE to design curriculum and courses, contributing to its successful accreditation. He serves as a panellist in the accreditation of various programmes and courses. He publishes research works in the areas of applied artificial intelligence, networking, as well as information and communications technology in education.

\section{Dr. Ing. Joao Ponciano P.E., University of Glasgow}

Eur. Ing. Dr. João Ponciano (CPE, LLB (Hons), M.Eng (Hons), M.A. (Distinction), PhD, FIET, C.Eng, MBCS, CITP, SFHEA, MIEEE, FinstLM) started his career as a researcher for the International Organisation for Nuclear Research (CERN) in Geneva, working on the West Area Neutrino Facility and North Area 48. Since then João has held several positions in teaching and management in higher education at institutions across the UK, Middle East, Africa and Asia. At Leeds Becket University, João specialised in teaching Mobile and Fixed Networking Technologies and introduced compendium-based teaching practices and led the design and implementation of the first Mobile and Distributed Computer Networks postgraduate course in UK.

João authored and managed a European Social Fund Project in Women in Engineering contributing to widening participation and inclusion of women engineers, developed and ran world-class innovative academic practice methods in Career Development, Employability and designed and managed staff workload models.

Since 2014, João developed and led transnational education partnerships in several countries in south East Asia and led a group of institutions under the group Star Education based in Singapore as Executive Dean and Senior Vice President. His management and leadership practices have warranted João the grade of Fellow of the Institute of Leadership and Management. In the UAE João led the review of all of the University of Wollongong's Dubai educational policies and procedures for accreditation under the Commission for Academic Accreditation (CAA) of the Ministry of Education (MoE).

João's has held public office as chairman of the Institution of Engineering and Technology in Greater Manchester, UK and been an international accreditor and panel chair under the Accreditation of Higher Education Programmes - Engineering Council UK. João has also held role as an Associate of the Higher Education Academy promoting and ensuring the professional standards and guidelines for higher education providers and leaders across the UK Higher Education Institutions.

João has published in the areas of educational practice, in particular employability and career development. He is an editorial board member of two international journals in the area of wireless and computer networks and consumer electronics.

João's achievements in academic practice have conferred him the grade of Senior Fellow of the Higher Education Academy.

\section{Dr. Sajjad Hussain, University of Glasgow}

Sajjad Hussain is a Lecturer in Electronics and Electrical Engineering at the University of Glasgow, UK. He has served previously at Electrical Engineering Department, Capital University of Science and Technology (CUST), Islamabad, Pakistan as Associate Professor. Sajjad Hussain did his masters in Wireless Communications in 2006 from Supelec, Gif-sur-Yvette and PhD in Signal Processing and Communications in 2009 from University of Rennes 1, Rennes, France. His research interests include 5G selforganizing networks, industrial wireless sensor networks and machine learning for wireless communications. Sajjad Hussain is a senior member IEEE and fellow Higher Education Academy.

\section{Prof. Muhammad Ali Imran P.E.,}

Muhammad Ali Imran (M'03, SM'12) Fellow IET, Senior Member IEEE, Senior Fellow HEA is a Professor of Wireless Communication Systems with research interests in self organised networks, wireless networked control systems and the wireless sensor systems. He heads the Communications, Sensing and Imaging CSI research group at University of Glasgow and is the Dean University of Glasgow, UESTC. 
He is an Affiliate Professor at the University of Oklahoma, USA and a visiting Professor at 5G Innovation Centre, University of Surrey, UK. He has over 20 years of combined academic and industry experience with several leading roles in multi-million pounds funded projects. He has filed 15 patents; has authored/co-authored over 400 journal and conference publications; was editor of 5 books and author of more than 20 book chapters; has successfully supervised over 40 postgraduate students at Doctoral level. He has been a consultant to international projects and local companies in the area of self-organised networks. He has been interviewed by BBC, Scottish television and many radio channels on the topic of 5G technology.

Prof. Sajid Sheikh Muhammad, National University of Computer and Emerging Sciences (FAST_NU), Lahore, Pakistan

Dr Sajid is a Professor of Electrical Engineering at the National University of Computer and Emerging Sciences which he has served since 2007. He got his doctorate with excellence from Graz University of Technology (Austria) in 2007, and grew from an Assistant Professor to a Full Professor from 2007 to 2016. He remained the Department Chair of Electrical Engineering from 2016 to 2019 for a successful tenure of 3 years.

\section{Dr. RAO NAVEED BIN RAIS, AJMAN UNIVERSITY, UAE}

Dr. Rais received his MS and PhD degrees in Computer Engineering with specialization in Networks and Distributed Systems from University of Nice, Sophia Antipolis, France in 2007 and 2011 respectively. Before that, he got BE in Computer Systems from National University of Science and Technology, Pakistan in 2002. He has experience of more than 15 years in teaching, research and industry R\&amp;D. Dr. Rais is author of several of publications in internationally recognized journals and conferences. His research interests include Network Protocols and Architectures, Information-Centric and Software-Defined Networks, Network Virtualization and Internet Naming and Addressing issues. He has also got several years of experience in Outcome-Based Education and Quality Assurance.

\section{Dr. Muhammad Rashid, Umm Al Qura University}

Muhammad Rashid has 20 years of academic and industrial experience in the domain of electrical and computer engineering. He is the author of more than 30 impact factor journals and around 40 international conferences. In the context of engineering education, he has published novel ideas for curriculum design and innovative courses.

\section{Dr. Boon Leing Tan, Xian International University}

Boon currently lectures at various universities, in the areas of Operations Management and Business Management, where he also supervises dissertation students at UG, PG and Doctoral levels. He is currently a guest professor with Xian International University and consults at SSC (Singapore). 


\title{
Outcome-Based Engineering Education: A Global Report of International OBE Accreditation and Assessment Practices
}

\author{
Junaid Qadir ${ }^{1}$, Aamir Shafi ${ }^{2}$, Ala Al-Fuqaha ${ }^{3,4}$, Abd-Elhamid M. Taha ${ }^{5}$, Kok-Lim Alvin Yau ${ }^{6}$, \\ Joao Ponciano ${ }^{7}$, Sajjad Hussain ${ }^{7}$, Muhammad Ali Imran ${ }^{7}$, Sajid Sheikh Muhammad ${ }^{2}$, Rao \\ Naveed bin Rais ${ }^{8}$, Muhammad Rashid ${ }^{9}$ and Boon Leing Tan ${ }^{10}$ \\ ${ }^{1}$ Information Technology University (ITU), Lahore, Pakistan \\ ${ }^{2}$ National University of Computer and Emerging Sciences (FAST-NU), Lahore, Pakistan \\ ${ }^{3}$ Hamad Bin Khalifa University (HBKU), Doha, Qatar \\ ${ }^{4}$ Western Michigan University (WMU), Kalamazoo, United States of America (USA) \\ ${ }^{5}$ Alfaisal University, Riyadh, Kingdom of Saudi Arabia (KSA) \\ ${ }^{6}$ Sunway University, Malaysia \\ ${ }^{7}$ University of Glasgow, United Kingdom \\ 8 Ajman University, United Arab Emirates (UAE) \\ ${ }^{9}$ Umm Al-Qura University, Mecca, Kingdom of Saudi Arabia (KSA) \\ ${ }^{10}$ PSB Academy, Singapore
}

\begin{abstract}
In this research paper, we present-as a geographically dispersed set of academics working in nine different countries: namely, Pakistan, United Kingdom, United Arab Emirates, United States of America, Saudi Arabia, Singapore, Qatar, China, and Malaysia-a global international perspective on Outcome-based Education (OBE) accreditation standards, practices, and attitudes. The OBE paradigm is now the underlying paradigm followed by global accreditation efforts such as the Washington Accord (ratified in 1989). The shift to OBE is so pronounced that some education experts identify the shift to OBE and accreditation as one of the top 5 major changes of the last 100 years. Although OBE is often criticized for straitjacketing education, and resisted by hesitant faculty members suspecting additional burden, studies show that the OBE movement, on the whole, has helped in improving the educational standards and outcomes by ensuring proper planning of curriculum and assessment and their alignment with the program objectives and desired outcomes. OBE is also flexible in the sense that it does not dictate the choice of specific education strategies or teaching methods-it only says what should be the outcome. New OBE schemes have also diversified in response to early misgivings about OBE (related to excessive paperwork, and bean-counting-like auditing) and now admit diverse types of evidence (including qualitative and quantitative, formative and summative, formal and informal assessments). The aim of this work is to present a synthesis of the experiences of an international set of authors and the sharing of the global best practices in the field related to accreditation and assessment. An extensive internal survey was conducted to collect data from these international academics. After processing the data, we have organized our analysis as a discussion on a range of accreditation stages and artifacts including vision/mission statements, program objectives and outcomes, curriculum planning, educational assessment strategies, common pitfalls, and iterative continuous improvement. This paper will be a helpful starting guide for faculty members new to OBE, while also offering a broader perspective to experienced faculty members and administrators.
\end{abstract}




\section{INTRODUCTION}

\section{A. What is Outcome-based Education?}

Outcome-based education (OBE) is considered the brainchild of the sociologist William Spady [1]. In the OBE paradigm, the instructional and assessment/evaluation practices are explicitly designed for ensuring the attainment of predefined learning outcomes that are aligned to broader, long-term educational objectives. OBE is now the underlying paradigm followed by global accreditation efforts such as the Washington Accord (ratified in 1989), which is an agreement to accept undergraduate engineering degrees that were obtained using outcome-based education (OBE) and accreditation (OBA) methods. The scale of the shift to OBE can be gauged from the fact that some educational experts are now calling it as one of the top five major changes in engineering education in the last 100 years [2].

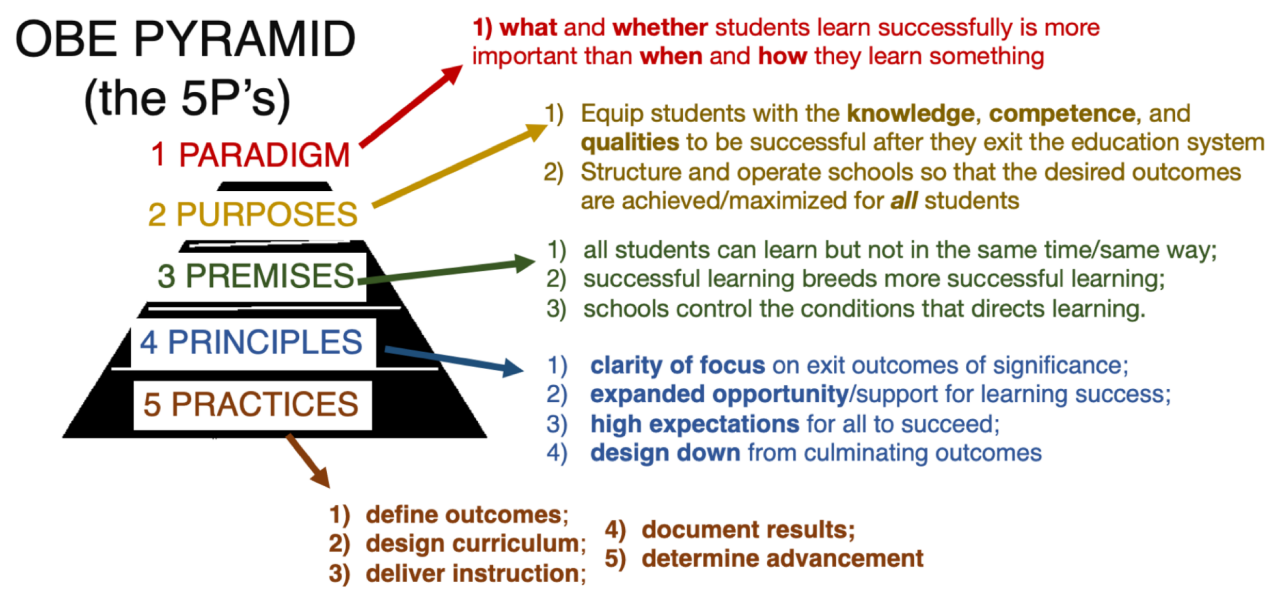

Figure 1: The OBE system can be understood through the illustrated "5 P's" OBE pyramid [Source: William Spady's OBE book [1]]

To illustrate the major ideas of OBE, Spady developed a pyramid of salient ideas (the 5 P's of OBE) that depict OBE purposes, premises, paradigm, principles, and practices (see Figure 1 for the details). It is important to reiterate the four principles of $O B E$, which are described as the need for: (1) clarity of focus on the culminating exit outcomes of significance; (2) expanded opportunity and support for learning success; (3) high expectations for all to succeed; and (4) designing down from the ultimate culminating outcomes. In the words of Spady [1]:

"Outcome-based Education means clearly focusing and organizing everything in an educational system around what is essential for all students to be able to do successfully at the end of their learning experiences." [1]

To understand OBE, it helps to compare it to the educational system that existed before it, which focused more on the input and output and, to some extent, the delivery process. In contrast to the preexisting models of quality evaluation (Figure 2), the system in OBE revolves around the pivot of outcomes-or the knowledge, skills, and attitudes that the learners can actually demonstrate at the time of the graduation. 


\begin{tabular}{l|l|l|l|}
\multicolumn{1}{c|}{ Input } & \multicolumn{1}{c|}{ Processes } & \multicolumn{1}{c|}{ Outputs } & \multicolumn{1}{c|}{ Outcomes } \\
\hline $\begin{array}{l}\text { Student } \\
\text { Background }\end{array}$ & $\begin{array}{l}\text { Programs and } \\
\text { services offered; }\end{array}$ & $\begin{array}{l}\text { Student grades; } \\
\text { graduation rates; } \\
\text { employment statistics }\end{array}$ & $\begin{array}{l}\text { Student learning; } \\
\text { knowledge; skills; } \\
\text { attitudes }\end{array}$ \\
\hline $\begin{array}{l}\text { Faculty } \\
\text { Background }\end{array}$ & $\begin{array}{l}\text { Faculty teaching } \\
\text { loads; class size; } \\
\text { tenure process; }\end{array}$ & $\begin{array}{l}\text { Credit hours delivered, } \\
\text { faculty development } \\
\text { activities }\end{array}$ & $\begin{array}{l}\text { Faculty publications; } \\
\text { citations; faculty } \\
\text { development }\end{array}$ \\
\hline $\begin{array}{l}\text { Educational } \\
\text { Resources }\end{array}$ & $\begin{array}{l}\text { Policies, } \\
\text { procedures, } \\
\text { governance }\end{array}$ & $\begin{array}{l}\text { Statistics on resource } \\
\text { availability, } \\
\text { participation rates }\end{array}$ & $\begin{array}{l}\text { Student learning } \\
\text { and growth }\end{array}$ \\
\hline
\end{tabular}

Figure 2: Measuring Input, Process, Output, Outcome. Outcomes play a pivotal role in the success of the outcome based education and assessment.

\section{B. Why Learn About International OBE and OBA Experiences \& Best Practices?}

The aim of this work is to present a synthesis of the experiences of an international set of authors and sharing of the global best practices in the field related to accreditation and assessment. In this paper, we present a global international perspective on OBE accreditation standards, practices, and attitudes. Apart from listing our observations, we also point out where relevant available guidelines and best practices that have been reported earlier in literature.

We find through our survey that there is a lot of diversity in the global OBE accreditation and assessment practices but also some unifying trends. The diversity reflects the fact that each university is different and serves different stakeholders and exists in a different environment. The commonality emerges from the fact that after the Washington Accord, there is increased uniformity in the expectations of what learning outcomes a graduate should be able to demonstrate.

Despite the commonalities, the learning curve for understanding OBE and OBA is steepespecially keeping in view the multifarious duties that a new faculty member has to perform. Faced with multiple tasks, most faculty members do whatever is necessary to complete the requirements without really understanding the rationale of $\mathrm{OBE}$ and subscribing to its enshrined principles and paradigm. Furthermore, many of the terminologies are easy to confuse and use incorrectly. The problem is exacerbated by the fact that learning across communities is made difficult by the use of different, and at times conflicting, terminologies in different parts of the world. These problems motivate the need for a comprehensive survey of OBE and OBA theory and a synthesis of best practices reported by experienced practitioners and this paper fills this gap.

\section{Contributions of this Work}

To the best of our knowledge, there is limited work on bringing the views and insights from academicians working on OBE related accreditation and assessment issues across the worldeven though there is plenty of scholarly work that has focused on documenting accreditation experiences of particular universities (see Table I) along with published guidelines to meet the accreditation requirements of particular accreditation agencies (cf. the manuals published 
by each accreditation board [e.g., Pakistan Engineering Council's OBA Manual 20141, and UK's Accreditation of Higher Education Programmes (AHEP) manual ${ }^{2}$ ). Our paper will be useful for practitioners-particularly new or inexperienced faculty members-who are unaware of the OBE/OBA philosophy and its best practices, and for whom the paper is offered as a comprehensive starting point. It will fruther help them to decide on possible appropriate procedures and systems best suited to their set up. The paper is also offered to more experienced administrators and faculty members such that they can be informed of alternative approaches that may be useful addressing issues they are struggling with. This effort is made possible because of involvement of experienced authors in an extensive internal survey, each of whom have been involved in OBE accreditation efforts for several years and are well aware of the full life cycle of such activities.

\begin{tabular}{|c|c|}
\hline Accreditation Experience Report From Which Country? & Ref. \\
\hline Bangladesh & {$[3]$} \\
\hline Malaysia & {$[4]$} \\
\hline Hong Kong & {$[5]$} \\
\hline India & {$[6]$} \\
\hline Kingdom of Saudi Arabia (KSA) & {$[7]$} \\
\hline Kuwait & {$[8]$} \\
\hline Pakistan & {$[9][10]$} \\
\hline Philippines & {$[11]$} \\
\hline South Africa & {$[12]$} \\
\hline Turkey & {$[13]$} \\
\hline United Arab Emirates (UAE) & {$[14]$} \\
\hline United States of America (USA) & {$[15][16]$} \\
\hline Multinational Reports & {$[17]$} \\
\hline
\end{tabular}

Table I: Accreditation Experience Reports From Various Countries: Some Related Work

\section{Organization of this Work}

The rest of the paper is organized as follows. A description of the demographics of the authors and the diversity of their institutes along with a brief primer on basic OBE terminologies is provided in Section II. We then present a discussion on strategic vision, objectives and outcomes, curriculum and instructional planning in Section III. This is followed by a discussion on quality management and continuous quality improvement (CQI) practices internationally in Section IV A discussion on assessment practices follows in Section $\mathrm{V}$. We present a synthesis of major insights learned through our survey and report of best practices and common pitfalls in Section VI. Finally the paper is concluded in Section VII.

\section{Preliminaries: Demographics, Methodology, And a Primer on OBE TERMINOLOGIES}

This section presents a discussion on the background of authors involved in this study. In addition, the section outlines the adopted research methodology and data acquisition practices. Finally, we introduce basic OBE terminologies in this section.

\footnotetext{
https://www.pec.org.pk/downloadables/Accreditation/PEC\%20OBA-Manual\%202014.pdf

2 https://www.engc.org.uk/ahep
} 


\section{A. Geographical Distribution of the Authors}

The authors of this paper are a geographically dispersed set of academics from Pakistan, United Kingdom, United Arab Emirates, United States of America, Saudi Arabia, Singapore, Qatar, China, and Malaysia (see Figure 3). Most of the authors have more than 10 years of experience in academia and have been involved in leadership roles related to accreditation and assessment (such as Dean, Vice-Dean, or Chairperson/Head of Department) while others have worked as members of accreditation, quality assurance, or assessment committees. All the authors have been directly involved in accreditation and assessment operations in at least one university for a minimum of one year. The authors are distributed across the globe with two authors working (or having worked) in Pakistan, and Saudi Arabia; three in a UK/China joint-program; more than one author in UK-based programs; and one author each in United Arab Emirates, Malaysia, Singapore.

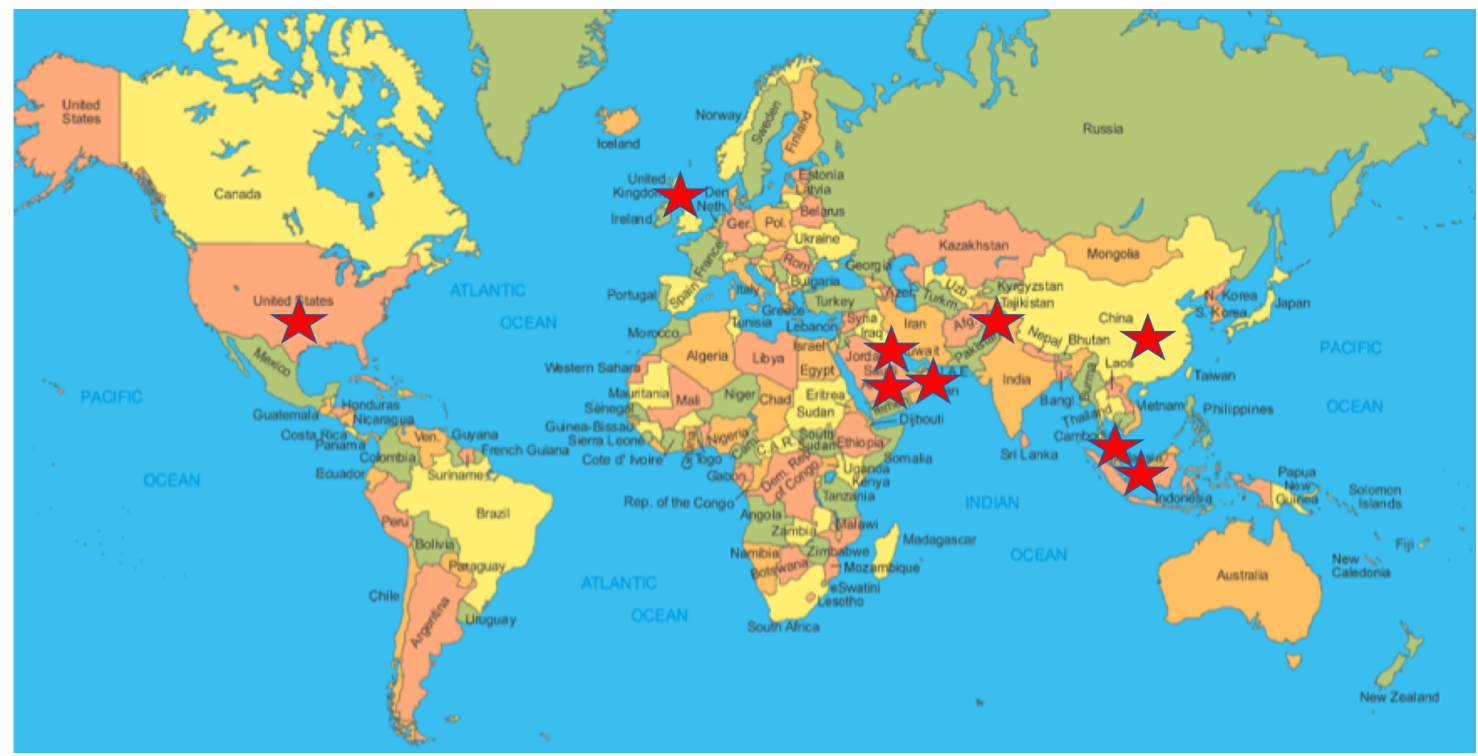

Figure 3: The nine different countries-Pakistan, United Kingdom, United Arab Emirates, United States of America, Saudi Arabia, Singapore, Qatar, China, and Malaysia - where the authors have worked on OBE-related matters in universities are shown with stars in this world map.

Some of the authors are accredited Program Evaluator (PEV) with Accreditation Board for Engineering and Technology (ABET), USA; Institution of Engineering and Technology (IET) in the UK; and Malaysian Qualifications Agency (MQA) in Malaysia. All the authors have reported that their respective accreditation organization follows and mandates outcome-based learning or outcome-based education. Most countries considered also are associated with the Washington Accord except United Arab Emirates (UAE), and the Kingdom of Saudi Arabia (KSA).

We note here that the perspectives presented in this paper are authors' own and may not necessarily represent that of their respective affiliate universities. Furthermore, the details of the universities are often omitted and presented in aggregate so that the focus is on the insights learned through the experience of the authors rather than that of a particular university or another. 


\section{B. Methodology Adopted}

In order to solicit feedback from the authors, we utilized an online questionnaire comprising 128 questions divided in 11 sections titled (i) General; (ii) OBE Terminologies; (iii) Quality Management System (QMS); (iv) Strategic Vision; (v) Curriculum Planning and Instruction Planning; (vi) Continuous Quality Improvement (CQI); (vii) Assessment; (viii) Formative Feedback; (ix) Experiences (Sharing Adopted Best Practices); (x) Program Inspection/Evaluation Experience (as a Program Evaluator); and (xi) Caveats. This serves us to get input from all of the authors on a consistent set of questions. Based on these answers received in these 11 sections, we have organized our findings in an outline similar (but not identical) to the section breakdown in the questionnaire.

In most cases, we have focused on the issues involved rather than on the particular institutes and persons involved to maintain privacy and anonymity. In some cases, we have reproduced text expressed by the authors in response to a question verbatim without identifying explicitly the specific author. We note that the perspectives provided in due course applies mostly to engineering programs, particularly electrical and computer engineering. However, most insights derived do generalize more broadly to all OBE instances. Notwithstanding, and while we have attempted to gather diverse perspectives from across the world and to qualify our statements, we do not claim that our survey reports findings are universally applicable, and do caution against overreaching generalizations.

The insights we have learned through our questionnaire-based data acquisition are presented in the remainder of this paper.

\section{Type of Universities and Degree Programs}

The authors work in universities of varying sizes ranging from small universities with 1500 students and 100 faculty members to very large universities with 100,000 students and over 5000 faculty members. There is also diversity in the focus of the authors' universities, with most universities being hybrid (focus on both research and teaching) while some universities focus on only research or teaching.

The programs managed by the authors range from those expecting OBE accreditation to those that have been accredited for more than 20 years. The OBE accreditation processes have mostly stabilized for the majority of the authors except for a minority. Most universities are accredited by the country-level accreditation bodies-however, ABET accreditation is also common in the Middle East. For transnational teaching (as is the case of the UK-China program of the University of Glasgow), it is common to follow both the standards that apply to the respective country.

The accreditation body come in many varieties: it may be (1) a statutory/governmental organization; (2) an engineering registration board (e.g., Pakistan Engineering Council); (3) a professional engineering institution (e.g., Institute of Engineers, Singapore); (4) an independent accreditation board (e.g., ABET). The Washington Accord only recognizes engineering programs accredited within the signatories' jurisdictions. In Table II, the relevant regional/national accreditation board is listed for the various countries in which the authors have worked and in which their accreditation experience is based. 


\begin{tabular}{|c|c|c|c|}
\hline No. & Country & Organization & Accreditation Manual/ Website Link \\
\hline 1 & China & $\begin{array}{l}\text { China Association for Science and Technology } \\
\text { (CAST) }\end{array}$ & http://english.cast.org.cn/ \\
\hline 2 & Malaysia & $\begin{array}{l}\text { Board of Engineers Malaysia (BEM)/ Engineer- } \\
\text { ing Accreditation Council (EAC) of Malaysia }\end{array}$ & https://www.mqa.gov.my/ \\
\hline 3 & Pakistan & Pakistan Engineering Council (PEC) & https://www.pec.org.pk/accreditation_guidelines.aspx \\
\hline 4 & Qatar & $\begin{array}{l}\text { Ministry of Education and Higher Education } \\
\text { (MOEHE) }\end{array}$ & http://www.edu.gov.qa/En/Pages/Home_en.aspx \\
\hline 5 & Saudi Arabia & $\begin{array}{l}\text { National Center for Academic Accreditation and } \\
\text { Assessment }\end{array}$ & https://www.ncaaa.org.sa/enportal/accreditation/ \\
\hline 6 & Singapore & Institute of Engineers, Singapore (IES) & https://www.ies.org.sg/Accreditation \\
\hline 7 & United Arab Emirates & Commission for Academic Accreditation (CAA) & https://www.caa.ae/caa/DesktopDefault.aspx \\
\hline 8 & United Kingdom & Engineering Council, United Kingdom (ECUK) & https://www.theiet.org/career/accreditation/academic-accreditation/ \\
\hline 9 & United States & $\begin{array}{l}\text { Accreditation Board for Engineering and Tech- } \\
\text { nology (ABET) }\end{array}$ & https://www.abet.org/accreditation/ \\
\hline
\end{tabular}

Table II: National Accreditation Organization Of Countries Surveyed

\section{OBE Terminologies}

Some common terminologies are used in relation with OBE (Table III). We find that confusingly sometimes multiple acronyms are used to refer to the same concept in different countries. The learning outcomes at the level of the course are typically called Course Learning Outcomes (CLOs) but at some places these are referred to as Intended Learning Outcomes (ILOs) [as per AHEP, UK] and Subject Learning Outcomes (SLOs) [e.g., at places in Malaysia and Hong Kong].

\begin{tabular}{|c|l|l|l|}
\hline Acronym & Term & Also Called & Explanation \\
\hline CLO & Course Learning Outcomes & ILO & $\begin{array}{l}\text { What students should be able to know, do, and value by the } \\
\text { end of a course. }\end{array}$ \\
\hline GA & Graduate Attributes & PLO, SLO, SO & $\begin{array}{l}\text { Statements that describe what students are expected to know } \\
\text { and be able to do by the time of graduation }\end{array}$ \\
\hline PEO & $\begin{array}{l}\text { Program Educational Objec- } \\
\text { tives }\end{array}$ & $\begin{array}{l}\text { What students should be able to know, do, and value by the } \\
\text { end of a course (Sometimes used to refer to desired outcomes } \\
\text { at the end of course units). }\end{array}$ \\
\hline PLO & Program Learning Outcomes & SO/SLO & $\begin{array}{l}\text { Broad statements that describe what graduates are expected to } \\
\text { attain within a few years of graduation. }\end{array}$ \\
\hline SO & Student Outcomes & SLO & $\begin{array}{l}\text { Statements that describe what students are expected to know } \\
\text { and be able to do by the time of graduation. }\end{array}$ \\
\hline SLO & Student Learning Outcomes & SO & $\begin{array}{l}\text { Statements that describe what students are expected to know } \\
\text { and be able to do by the time of graduation. }\end{array}$ \\
\hline
\end{tabular}

Table III: Important terms (and their synonyms) used in global OBE accreditation

The learning outcomes at the level of the program (the outcomes that the students are expected to demonstrate at the time of the graduation) are also known differently. These are mostly called Program Learning Outcomes (PLOs), but at some places these are referred to as Graduate Attributes (GAs) (in the Washington Accord) or Student Outcomes (SOs), e.g., with ABET. In some places, different organizations are followed (e.g., in KSA, NCAAA and ABET are usually followed) with the organizations having different terminologies for equivalent concepts.

Some authors have reported using the term Student Learning Outcome (SLO) as equivalent to PLO (or to SO). Unfortunately, SLO is also used to refer to Subject Learning Outcomes, which is equivalent to CLO and is used in Malaysia. 
Difference between objective and outcome: objectives are usually long-term while outcomes are short-term. In OBE terminology, the most important objective-related term is Program Educational Objectives (PEOs), which are broad statements that describe what graduates are expected to attain within a few years (typically, 3-5 years) after graduation.

At a high level, we can say that there are two types of outcomes - those that are defined at the program level, i.e., outcomes expected at graduation time, and others at the course level, i.e., outcomes expected at the time of clearing a course. Unfortunately, still, the terminology can be conflicting here with some acronyms having more than one usage and different terms being used for the same idea. We introduce the main terms next.

- Program Learning Outcomes (PLOs) _-Program learning outcomes are statements that describe what the knowledge, skills and attitudes students should have at the time of graduation from an engineering program. PLOs are discipline agnostic. These are also referred to as Graduate Attributes (GA) (see Table VI for the Washington Accord's recommended GAs). The term PLO also has synonyms, which we describe next.

- Student Outcomes (SOs) - "Student outcomes describe what students are expected to know and able to do by the time of graduation. These relate to the knowledge, skills, and behaviors that students acquire as they progress through the program. [18]" SOs refer to the same concept as PLOs and is the term preferred by ABET. In some places, SOs and PLOs are sometimes referred to as Student Learning Outcomes (SLOs).

- Course Learning Outcomes (CLOs) - this refers to "What students should be able to know, do, and value by the end of a course."; in some jurisdictions CLOs are called Subject Learning Outcome (SLO) [e.g., in Malaysia] or Intended Learning Outcome (ILO) [e.g., in the UK].

\section{Strategic Vision, Objectives and Outcomes, Curriculum And INSTRUCTIONAL PLANNING}

This section is organized in the following three subsections: Section III-A (Strategic Vision); Section III-B (Curriculum Planning and Instruction Planning); and Section III-C (Mapping of Outcomes to Performance Indicators).

\section{A. Strategic Vision}

"To begin with the end in mind means to start with a clear understanding of your destination. It means to know where you're going so that you better understand where you are now so that the steps you take are always in the right direction." - Covey [19]

1) Vision vs. Mission: The vision statement is a concise articulation of what the institute stands for and what is its ultimate purpose. In other words, the vision refers to where you want to be in the future. The mission statement, on the other hand, is closely linked to the vision, and provides clear and more detailed direction for the present and the future. The mission statement of an institute articulates its raison d'être, or reason of existence. The values of an organization are the principles through which the institute operates and seeks to achieve the vision and its mission.

The task of designing an institute's vision, mission, and values is an all-important exercise for these articulate the beliefs and aspirations of the institution. These statements should be short, 


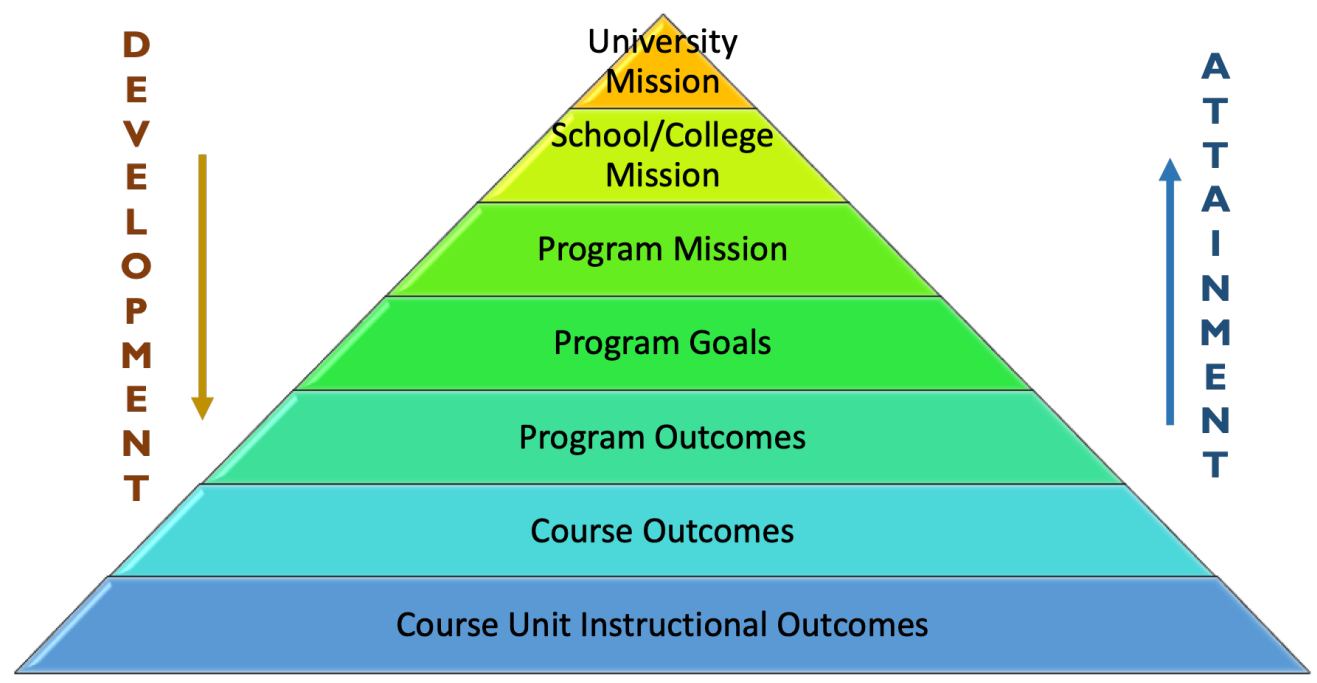

Figure 4: The outcomes pyramid. The desired outcomes towards the bottom are developed and shaped by those listed above. Also, the attainment of the bottom outcomes are necessary for attaining the outcomes listed on top.

crisp, and unambiguous. It is important that all the stakeholders-including the students, faculty members and the employers, and not just the administrators - have a say in this. This promotes clearer communication and transparency and ownership. This however becomes a challenge in larger universities with many colleges and departments. One way to keep the vision in line with the original purpose of the university is to involve like-minded experts. For example, one author notes "The board of trustees is involved at the university level. At the department and college levels, the advisory boards are involved."

As per OBE recommendations, almost all the authors have reported that their universities have clear vision and mission statements-often at multiple levels, i.e., at the institute, college, and department/program.

Some sample vision/mission statements are linked below for reference in Table IV

\begin{tabular}{|c|c|}
\hline University Name & URL \\
\hline Alfaisal University, KSA & https://coe.alfaisal.edu/en/ee-program-mission-education-objectives \\
\hline Ajman University, UAE & https://www.ajman.ac.ae/en/about/mission-vision-and-values \\
\hline Hamad Bin Khalifa University, Qatar & https://www.hbku.edu.qa/en/about-hamad-bin-khalifa-university \\
\hline Information Technology University of Punjab, Pakistan & https://itu.edu.pk/vision-mission-statement/ \\
\hline National University of Computer and Emerging Sciences, Pakistan & https://www.nu.edu.pk/vision-and-mission \\
\hline PSB Academy, Singapore & https://www.psb-academy.edu.sg/about/vision-mission-and-values \\
\hline Sunway University, Malaysia & https://sunway.edu.my/ipoh/vision-mission \\
\hline Umm Al-Qura University, KSA & https://uqu.edu.sa/en/main/54289 \\
\hline University of Glasgow, UK & https://www.gla.ac.uk/explore/strategy/visionandmission/ \\
\hline Western Michigan University, USA & https://wmich.edu/about/mission-history \\
\hline
\end{tabular}

Table IV: Sample Mission and Vision Statements for Universities

2) Program Education Objectives (PEOs): PEOs play a central role in the effectiveness of OBE. Objectives are general, usually few in number, and broad in scope. Objectives may represent a hard-to-measure "wish-list" that is not directly assessed. The essence of OBE is that the curriculum and instruction and assessment are all to be planned around stated longerterm broad objectives and immediate shorter-term outcomes. Instead of an overly quantitative 
and prescriptive model demanding a cookie-cutter engineering curricula-such as the one that existed before the introduction of OBE-based EC2000, the use of PEOs allows each institute to define success for itself and set its own goals. This allows the institute flexibility to create effective programs as per the context and the needs of the stakeholders.

PEOs are broad goals and it is recommended that they be [20]: consistent with the mission of the institution and the needs of the key stakeholders; comprehensive; clearly defined; measurable; and flexible and not narrow or unduly limited. In [20], the authors describe how to go about creating, assessing, and documenting PEOs, and offer guidelines on how to meet ABET EC2000 Criterion 2. It is worth noting that the content of the educational objectives itself is not subject to challenge by ABET as long as the formulation guidelines prescribed by Criterion 2 were clearly observed. The authors recommend that the institute aiming for accreditation should prepare, at a minimum, to:

- provide a list of PEOs (which should be well-advertised to all stakeholders including students);

- demonstrate the consistency of the PEOs with the mission and vision of the institution;

- identify significant stakeholders [also called constituencies] of the program;

- describe the processes that are used to establish and review the PEOs and establish that the various stakeholders are actively involved in these processes; and

- demonstrate that the processes are working and producing the desired results and that feedback is being used to refine PEOs and the curricula and instruction as per need;

Common issues with PEOs include the articulation of PEOs as statements that do not describe accomplishments a few years after graduation or the lack of involvement of constituents/stakeholders in the review of PEOs.

For the reference of the readers, we are linking to some sample PEOs for electrical/electronics engineering program in Table $\mathrm{V}$.

\begin{tabular}{|l|l|}
\hline University Name & URL \\
\hline Alfaisal University, KSA & https://coe.alfaisal.edu/en/ee-program-mission-education-objectives \\
\hline Ajman University, UAE & https://tinyurl.com/ajman-university-bs-ee \\
\hline Information Technology University of Punjab, Pakistan & https://itu.edu.pk/admissions/bs-electrical-engineering/ \\
\hline National University of Computer and Emerging Sciences, Pakistan & $\overline{\text { https://www.nu.edu.pk/campus/missionvision/Electrical\%20Engineering }}$ \\
\hline Umm Al-Qura University, KSA & https://uqu.edu.sa/en/ee/19378 \\
\hline University of Glasgow and UESTC Joint Educational Programme, UK & http://en.uestc.edu.cn/info/1097/2565.htm \\
\hline Western Michigan University, USA & https://wmich.edu/electrical-computer/electrical-objectives \\
\hline
\end{tabular}

Table V: Sample Program Educational Objectives (PEOs) (Electrical/Electronic Engineering Programs)

3) Program Learning Outcomes (PLOs): It is not uncommon to utilize the PLOs or SOs that are mandated by the respective accreditation organization verbatim in toto. Some authors have reported that their accreditation organization more or less standardizes their instructional practices (things such as the textbook that must be followed; the lesson plan that must be followed; etc.) to a large extent (e.g., NCAAA in KSA). In some cases, some additional outcomes are added. Washington Accord (WA) recommends a set of 12 Graduate Attributes (GA) which have been adopted in many places including in Pakistan where the same 12 GAs are recommended as the 12 mandatory PLOs.

\footnotetext{
https://www.ieagreements.org/assets/Uploads/Documents/Policy/Graduate-Attributes-and-Professional-Competencies.pdf
} 


\begin{tabular}{|c|c|c|}
\hline No. & Graduate Attribute (GA) & Description \\
\hline GA1 & Engineering Knowledge & $\begin{array}{l}\text { An ability to apply knowledge of mathematics, science, engineering fundamentals and } \\
\text { an engineering specialization to the solution of complex engineering problems }\end{array}$ \\
\hline GA2 & Problem Analysis & $\begin{array}{l}\text { An ability to identify, formulate, research literature, and analyze complex engineering } \\
\text { problems reaching substantiated conclusions using first principles of mathematics, } \\
\text { natural sciences and engineering sciences. }\end{array}$ \\
\hline GA3 & $\begin{array}{l}\text { Design/Development of Solu- } \\
\text { tions }\end{array}$ & $\begin{array}{l}\text { An ability to design solutions for complex engineering problems and design systems, } \\
\text { components or processes that meet specified needs with appropriate attention to public } \\
\text { health and safety, cultural, societal, and environmental considerations. }\end{array}$ \\
\hline GA4 & Investigation & $\begin{array}{l}\text { An ability to investigate complex engineering problems in a methodical way including } \\
\text { literature survey, design and conduct of experiments, analysis and interpretation of } \\
\text { experimental data, and synthesis of information to derive valid conclusions. }\end{array}$ \\
\hline GA5 & Modern Tool Usage & $\begin{array}{l}\text { An ability to create, select and apply appropriate techniques, resources, and modern } \\
\text { engineering and IT tools, including prediction and modeling, to complex engineering } \\
\text { activities, with an understanding of the limitations. }\end{array}$ \\
\hline GA6 & The Engineer and Society & $\begin{array}{l}\text { An ability to apply reasoning informed by contextual knowledge to assess societal, } \\
\text { health, safety, legal and cultural issues and the consequent responsibilities relevant to } \\
\text { professional engineering practice and solution to complex engineering problems. }\end{array}$ \\
\hline GA7 & Environment and Sustainability & $\begin{array}{l}\text { An ability to understand the impact of professional engineering solutions in societal } \\
\text { and environmental contexts and demonstrate knowledge of and need for sustainable } \\
\text { development. }\end{array}$ \\
\hline GA8 & Ethics & $\begin{array}{l}\text { Apply ethical principles and commit to professional ethics and responsibilities and } \\
\text { norms of engineering practice. }\end{array}$ \\
\hline GA9 & Individual and Team Work & $\begin{array}{l}\text { An ability to work effectively, as an individual or in a team, on multifaceted and /or } \\
\text { multidisciplinary settings. }\end{array}$ \\
\hline GA10 & Communication & $\begin{array}{l}\text { An ability to communicate effectively-orally and in writing-on complex engineer- } \\
\text { ing activities with the engineering community and the society at large (and compre- } \\
\text { hend/write effective reports; design documentation; make effective presentations; and } \\
\text { give/receive clear instructions.) }\end{array}$ \\
\hline GA11 & Project Management & $\begin{array}{l}\text { An ability to demonstrate management skills and apply engineering principles to } \\
\text { one's own work, as a member and/or leader in a team, to manage projects in a } \\
\text { multidisciplinary environment. }\end{array}$ \\
\hline GA12 & Lifelong Learning & $\begin{array}{l}\text { An ability to recognize importance of, and pursue lifelong learning in the broader } \\
\text { context of innovation and technological developments. }\end{array}$ \\
\hline
\end{tabular}

Table VI: International Engineering Alliance (IEA) Washington Accord (WA) Graduate Attributes (Also referred to as Program Learning Outcomes (PLO) and Student Outcomes (SO) in some quarters)

In the US, Accreditation Board for Engineering and Technology (ABET) is the accreditation board that accredits post-secondary education programs in applied and natural science, computing, engineering and engineering technology. In 1996, the ABET Board of Directors adopted the new set of standards, referred to as Engineering Criteria 2000 (EC2000). It was in ABET EC2000 where the shift of the basis for accreditation from inputs - such as what is taught-to outputs - what is learned and what the student can do-was first effected. The EC2000 criteria specified 11 program learning outcomes (or student outcomes) and required programs to assess and demonstrate their students' achievement in terms of these outcomes. Several subscribing to the ABET model have adopted their recommended 11 SOs-Criterion 3 (a)-(k) student outcomes (listed in Table VII), which have been unchanged since they were adopted as part of EC2000.

ABET, in a change made in 2017 and applicable beginning 2019-20 cycle 4 , has made a change to simplify and aggregate the PLOs/SOs from 11 SOs to just 7 SOs: which are numbered as SO 


\begin{tabular}{|l|l|l|}
\hline Number & Student Outcome & $\begin{array}{l}\text { Match in Wash- } \\
\text { ington } \\
\text { Accord }\end{array}$ \\
\hline $\mathbf{( 3 a})$ & an ability to apply knowledge of mathematics, science, and engineering & GA 1 \\
\hline $\mathbf{( 3 b )}$ & an ability to design and conduct experiments, as well as to analyze and interpret data & GA 4 \\
\hline $\mathbf{( 3 c )}$ & $\begin{array}{l}\text { an ability to design a system, component, or process to meet desired needs within } \\
\text { realistic constraints such as economic, environmental, social, political, ethical, health } \\
\text { and safety, manufacturability, and sustainability }\end{array}$ & GA 3 (part of) \\
\hline $\mathbf{( 3 d )}$ & an ability to function on multidisciplinary teams & GA 9 \\
\hline $\mathbf{( 3 e )}$ & an ability to identify, formulate, and solve engineering problems & GA 3 (part of) \\
\hline $\mathbf{( 3 f )}$ & an understanding of professional and ethical responsibility & GA 8 \\
\hline $\mathbf{( 3 g})$ & an ability to communicate effectively & GA 10 \\
\hline $\mathbf{( 3 h )}$ & $\begin{array}{l}\text { the broad education necessary to understand the impact of engineering solutions in a } \\
\text { global, economic, environmental, and societal context }\end{array}$ & GA \& 7 \\
\hline $\mathbf{( 3 i )}$ & a recognition of the need for, and an ability to engage in life-long learning & GA 12 \\
\hline $\mathbf{( 3 j})$ & a knowledge of contemporary issues & GA 6 \& 7 \\
\hline $\mathbf{( 3 k})$ & $\begin{array}{l}\text { an ability to use the techniques, skills, and modern engineering tools necessary for } \\
\text { engineering practice }\end{array}$ & GA 5 \\
\hline
\end{tabular}

Table VII: ABET Criterion 3. Student Outcomes-Mandatory outcomes (a) through (k) are listed-With Their Analogues Among Mandatory Washington Accord Graduate Attributes.

(1) through (7). The new SOs and their mapping to the old 11 SOs are documented in Table VIII

\begin{tabular}{|c|c|c|}
\hline Number & Revised Student Outcome Description & Covers Old SOs \\
\hline (SO 1) & $\begin{array}{l}\text { an ability to identify, formulate, and solve complex engineering problems by applying } \\
\text { principles of engineering, science, and mathematics }\end{array}$ & $(3 a) \&(3 e) \&(3 k)$ \\
\hline (SO 2) & $\begin{array}{l}\text { an ability to apply engineering design to produce solutions that meet specified needs } \\
\text { with consideration of public health, safety, and welfare, as well as global, cultural, social, } \\
\text { environmental, and economic factors }\end{array}$ & $(3 b) \&(3 k)$ \\
\hline (SO 3) & an ability to communicate effectively with a range of audiences & $(3 g)$ \\
\hline (SO 4) & $\begin{array}{l}\text { an ability to design a system, component, or process to meet desired needs within realistic } \\
\text { constraints such as economic, environmental, social, political, ethical, health and safety, } \\
\text { manufacturability, and sustainability }\end{array}$ & $(3 f) \&(3 h) \&(3 j)$ \\
\hline (SO 5) & $\begin{array}{l}\text { an ability to function effectively on a team whose members together provide leadership, } \\
\text { create a collaborative and inclusive environment, establish goals, plan tasks, and meet } \\
\text { objectives }\end{array}$ & $(3 d)$ \\
\hline (SO 6) & $\begin{array}{l}\text { an ability to develop and conduct appropriate experimentation, analyze and interpret data, } \\
\text { and use engineering judgment to draw conclusions }\end{array}$ & $(3 b) \&(3 k)$ \\
\hline (SO 7) & $\begin{array}{l}\text { an ability to acquire and apply new knowledge as needed, using appropriate learning } \\
\text { strategies }\end{array}$ & $(3 i)$ \\
\hline
\end{tabular}

Table VIII: Revised ABET Criterion 3. Student Outcomes-Mandatory outcomes (SO 1) through (SO 7) are listed-With Their Analogues Among Previous SOs.

In the UK, the accreditation standards are set by the regulatory body for the profession, namely Engineering Council (EC) of UK (EC-UK), in conjunction with the discipline-specific Professional Engineering Institutions (PEIs). EC-UK is responsible for setting the overall requirements for the Accreditation of Higher Education Programmes (AHEP) in engineering, in line with the UK Standard for Professional Engineering Competence (UK-SPEC) 5 [21]. Unlike ABET, EC-UK is not in the business of conducting accreditation itself. Instead, this task is performed by several professional engineering institutions licensed by EC-UK to carry out the process of accreditation. EC-UK first published AHEP framework based on OBE in 2004. The same 
outcomes-focused approach is adopted by UK-SPEC. Since 2006, the Quality Assurance Agency (QAA), UK's quality body for higher education, has also adopted EC-UK's learning outcomes as the subject benchmark statement for engineering.

The EC (EC 2014) has 40 learning outcomes listed and grouped into six broad areas of learning, which are: (1) Science and mathematics; (2) Engineering analysis; (3) Design; (4) Economic, legal, social, ethical and environmental context; (5) Engineering practice; and (6) Additional general skills. A comparison of the classical 11 ABET Student Outcomes and the 40 EC learning outcomes shows a significant degree of overlap (as shown in Figure 5).

\begin{tabular}{|c|c|c|c|c|c|c|}
\hline \multirow[b]{2}{*}{ ABET Student Outcomes } & \multicolumn{6}{|c|}{ EC Broad Areas of Learning } \\
\hline & $\begin{array}{l}\text { Science and } \\
\text { Mathematics }\end{array}$ & $\begin{array}{c}\text { Engineering } \\
\text { Analysis }\end{array}$ & Design & $\begin{array}{c}\text { Economic, legal, } \\
\text { social, ethical and } \\
\text { environmental } \\
\text { context }\end{array}$ & $\begin{array}{l}\text { Engineerin } \\
\text { g practice }\end{array}$ & $\begin{array}{c}\text { Additional } \\
\text { general skills }\end{array}$ \\
\hline $\begin{array}{l}\text { An ability to apply knowledge of mathematics, science } \\
\text { and engineering. }\end{array}$ & $\mathrm{X}$ & $\mathrm{X}$ & & & & \\
\hline $\begin{array}{l}\text { An ability to design and conduct experiments, as well as } \\
\text { to analyse and interpret data. }\end{array}$ & & $\mathrm{X}$ & & & $\mathrm{X}$ & \\
\hline $\begin{array}{l}\text { An ability to design a system, component, or process to } \\
\text { meet desired needs within realistic constraints.... }\end{array}$ & & & $\mathrm{X}$ & & $\mathrm{X}$ & \\
\hline An ability to function on multidisciplinary teams. & & & & & $\mathrm{X}$ & $\mathrm{X}$ \\
\hline $\begin{array}{l}\text { An ability to identify, formulate and solve engineering } \\
\text { problems. }\end{array}$ & & $\mathrm{X}$ & $\mathrm{X}$ & & & \\
\hline $\begin{array}{l}\text { An understanding of professional and ethical } \\
\text { responsibility. }\end{array}$ & & & & $\mathrm{X}$ & & $\mathrm{X}$ \\
\hline An ability to communicate effectively. & & & $\mathrm{X}$ & & & \\
\hline $\begin{array}{l}\text { The broad education necessary to understand the impact } \\
\text { of engineering solutions in a global...... }\end{array}$ & & & & & $\mathrm{X}$ & \\
\hline $\begin{array}{l}\text { A recognition of the need for, and an ability to engage in } \\
\text { life-long learning. }\end{array}$ & & & & & & $\mathrm{X}$ \\
\hline A knowledge of contemporary issues. & & & & $\mathrm{X}$ & & \\
\hline $\begin{array}{l}\text { An ability to use the techniques, skills, and modern } \\
\text { engineering tools necessary for engineering practice. }\end{array}$ & $\mathrm{X}$ & & & & & $\mathrm{X}$ \\
\hline
\end{tabular}

Figure 5: Engineering Council of UK (EC-UK)'s Broad Areas of Learning vs. ABET (USA) Classical Student Outcomes (3a: 3k) (Source: Anwar and Richards [15])

\section{B. Curriculum Planning and Instruction Planning}

Curriculum planning is an important first step towards implementing OBE. This involves (1) writing CLOs; (2) mapping CLOs to PLOs/SOs/PIs; amd (3) planning assessments to gauge performance in CLOs. Curriculum planners also need to devise a strategy to collect CLOs performance data and use it for quantifying performance at the PLOs/SOs level. It is recommended for institutes embarking upon their OBE journey to utilize senior faculty members in the curriculum planning stage and take a "top- down" approach where mappings between CLOs to PLOs/SOs are first established and later shared with all faculty members in the department.

Authors were asked to explain the best practices in mapping outcomes at course and program level. Common questions amongst new faculty members in this context include: (1) is one CLO mapped to a single or multiple SOs/PLOs/PIs?; and (2) is it possible for a CLO to not map to any $\mathrm{SO} / \mathrm{PLO} / \mathrm{PI}$ ?

We found out that to facilitate mapping, and follow-up assessments, it is not uncommon to restrict the mapping of each CLO to only one PLO/SO or PI. However there are exceptions 
too where CLOs are mapped to limited number of PLOs. Some even mandate only one to one mapping, while others mandate CLO to be mapped to no more than $2 / 3$ PIs. This is done to make assessment and evaluation effective while minimizing its overhead.

It is possible to have CLOs that do not map to any PI or SO-thus not all assessments are OBE based. Only assessments that map to CLOs (that in turn mapped to PLOs/SOs) have OBE assessment. However, this practice is not universally applied. Meanwhile, one author noted that at their institutions "CLOs are mapped to either SOs or PLOs directly, with no intermediates."

Depending on the number of enrolled students in a particular course, it is common to split students into sections of manageable sizes. It is also possible that different instructors teach parallel sections of the same course. In such instances, the authors have reported that it is common to have uniformity of curriculum and assessment strategy with most elements in this regard pre-planned. In many cases, the major examinations are the same for the various sections. Some laxity is allowed for minor assessment tools (such as quizzes and assignments). Some authors have reported the use of a "course mentor" or a "course coordinator" to help ensure uniformity across different sections being taught the same subject the same year.

1) Using the Understanding By Design Framework For Planning: The very influential Understanding by Design (UbD) framework [22] proposed by Grant Wiggins and Jay McTighe recommends following three stages in planning a program or a course curriculum.

Stage One-Identify Desired Results: In the first stage of UbD, the instructor plans the learning goals or objectives of the lesson, unit, or course.

Stage Two-Determine Acceptable Evidence: At this stage, the important question is to deliberate over what evidence would be acceptable for establishing that the students have achieved the desired goals (which were devised in Stage One)?

Stage Three-Plan Learning Experiences and Instruction: In the UbD framework's last stage, the instruction/curriculum/teaching strategy is planned. UbD is called backward design since in practice instructors usually start by planning their teaching strategy rather than think about the big "understanding" and learning goals and appropriate evidence that can establish the attainment of these objectives.

The UbD authors recommend that at this stage the instructors can deliberate over, "(1) What enabling knowledge (facts, concepts, principles) and skills (processes, procedures, strategies) will students need to perform effectively and achieve desired results?; (2) What activities will equip students with the needed knowledge and skills?; (3) What will need to be taught and coached, and how should it best be taught, in light of performance goals?; and (4) What materials and resources are best suited to accomplish these goals?" [22].

This approach is useful when we are planning to not merely cover topics, but to teach for understanding and transfer (the ability to apply knowledge in new domains) and the attainment of the planned learning outcomes. This is helpful at various levels including course level. It can also be useful in extension for program-level deliberations. The interested readers are referred to the definitive reference on this [22] written by the authors of this framework for more details.

2) Constructive Alignment: Constructive alignment [23] is another OBE-aligned framework for curriculum planning. Constructive alignment has two aspects: the first (the 'constructive' aspect) refers to what the learner does-which is to construct meaning through relevant learning 


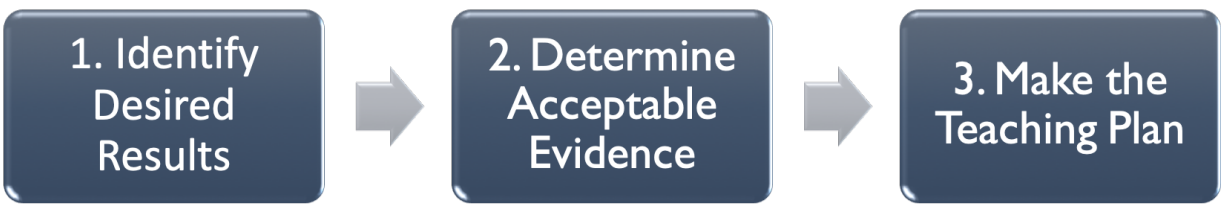

Figure 6: Understand by Design: The Three Stages of Backward Design

activities; and the second (the 'alignment' aspect) refers to what the instructor does-which is to set up a learning environment incorporating suitable learning activities (including teaching and assessment methods) that are aligned with the desired learning outcomes and help achieve these. It is important in a framework relying on constructive alignment that the triad of learning outcomes, assessment methodology, and instructional methodology are aligned and feed into each other (see Figure 7).

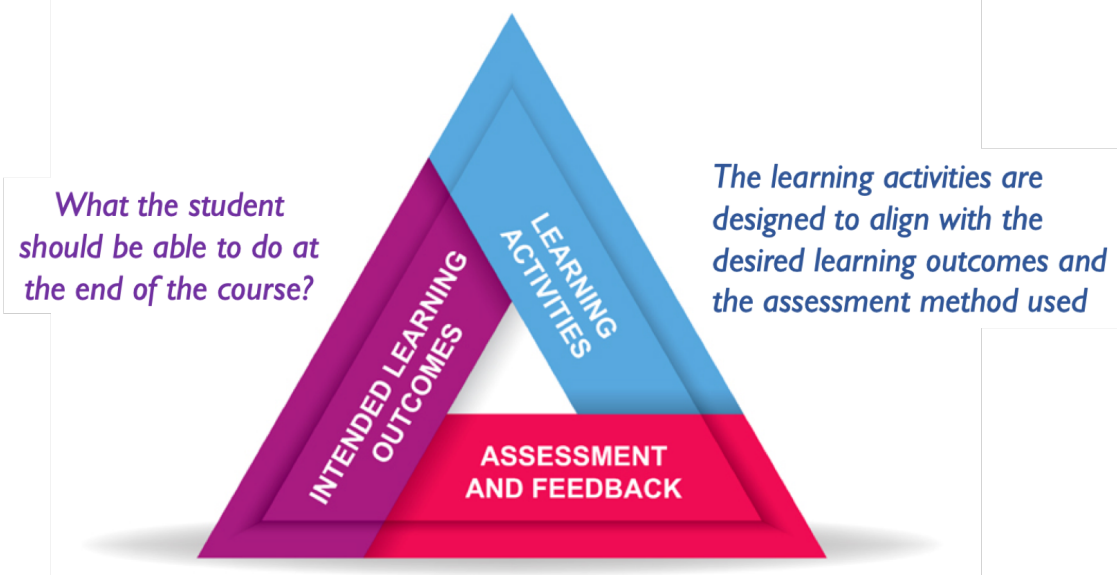

The assessment methodology is aligned with the desired outcomes. (This will signal to the students what is important to learn and how it should be learned)

Figure 7: A depiction of the philosophy of Constructive Alignment [23] [Modified from https://tinyurl.com/NTU-OBTL]

\section{Mapping of Outcomes to Performance Indicators}

"The development of performance indicators is unquestionably the most critical part of developing a systematic and meaningful data collection process around program assessment and improvement. ${ }^{26}$

Since OBE is outcome-based, it is important to have a mechanism that can ascertain the extent of the success of the educational process in ensuring the attainment of the PLOs/SOs. To assess the attainment of the PLOs (or SOs in ABET terminology), one common approach is to have

https://www.abet.org/wp-content/uploads/2017/02/Student-Outcomes-and-Performance-Indicators_revised.pdf 
measurable performance indicators (PIs) that are evaluated to measure the attainment of PLOs. PIs are comparable to the concept of "leading indicators" used in economics, which is used to "identify specific characteristics of the economy that are significant indicators of the current state and predict future trends." [24]. Thus, multiple measurable PIs are often associated with PLOs/SOs to verify their attainment. In some other terminologies (e.g., KSA's NCAAA), both PLOs and CLOs are expected to be measureable, and are therefore view as PIs at the program and course levels, respectively.

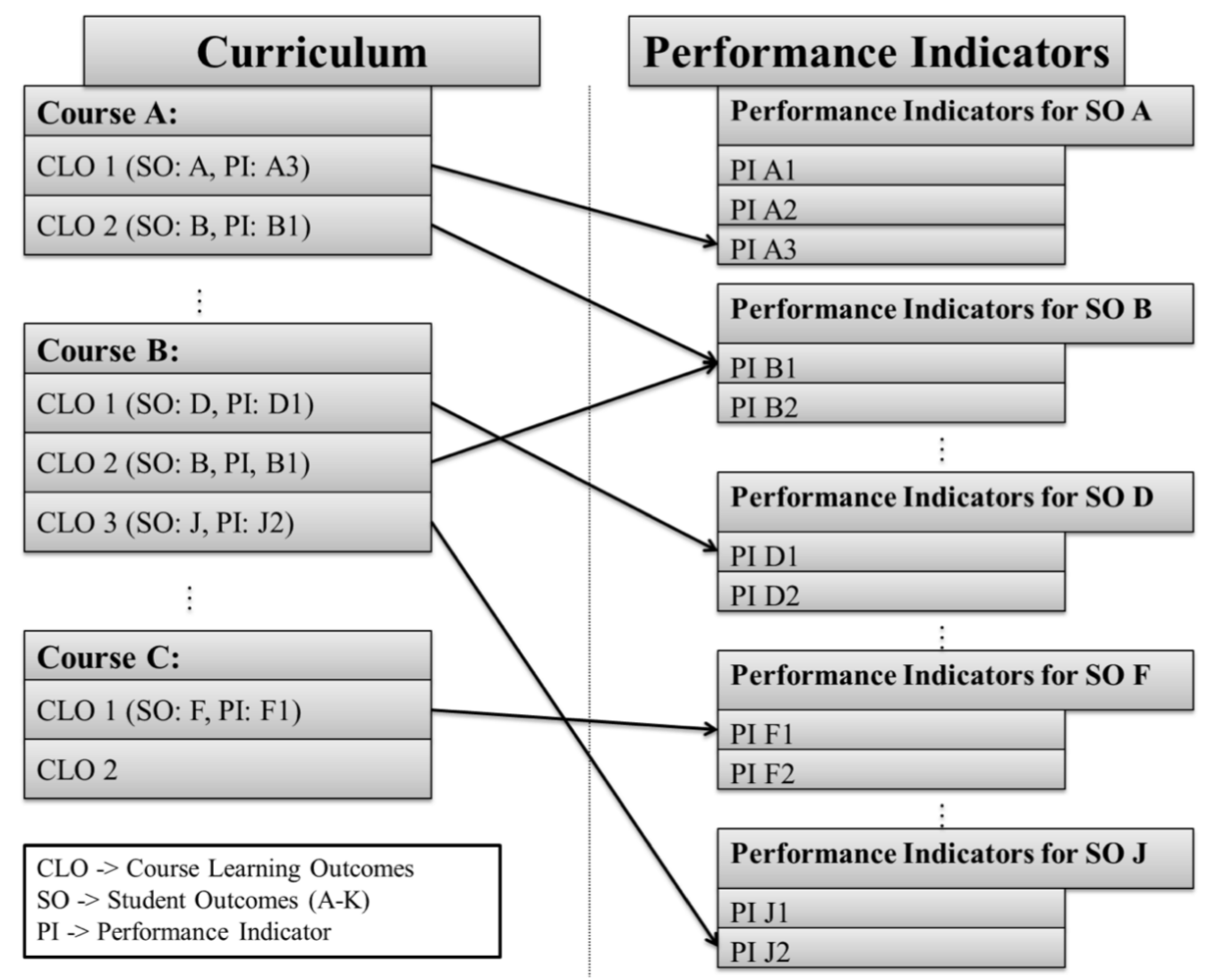

Figure 8: Example mapping of CLO to PI to PLO/SO mapping (Source: Shafi et al. [7])

There are two essential parts of writing a PI: (1) Subject content; (2) Action verb: direct students to a specific performance (e.g., "list," "analyze," "apply"). PIs are thus written like the CLOs, which are also measured and often written with an action verb commensurate to the level of the planned outcomes. Rubrics are also common for evaluating performance against performance indicators. A four level model is common (e.g., poor/non-existent; developing; developed; exemplary).

Some responses to a question relevant to this topic provided by the authors are reproduced below.

Question-Does your department/college/university define Performance Indicators (PIs) for each CLO? Does your department/college/university define Performance Indicators (PIs) for each PLO? 
"In the NCAAA lore, PLOs and CLOs are measurable, unlike ABET SOs, which are dense, and guiding."

"Yes, we define PIs for each CLO and PLO."

It is worth highlighting here what should be avoided while framing PI (and CLOs, which should also be measurable and concrete). While articulating these outcomes, the focus should be on writing PIs from the perspective of what the student should be able to demonstrate by means of the assessment. Verbs that are vague or non-observable-such as appreciate, believe, know, learn, realize, think or understand—should be avoided [25].

\section{Quality Management and Continuous Quality Improvement (CQI)}

\section{A. Quality Policy and Quality Management System}

Most of the organizations of the authors involved either have a quality policy in place, or are in the process of formally formulating a policy. Some of these policies are publicly accessible while others are locally available. The resulting manuals or guidelines may act as useful starting resources for universities interested in formalizing their own quality policy. Examples include those shared by: (1) Ajman University]? (2) UK Quality Assurance Agency (QAA)'s Quality Code for Higher Education 20188, and (3) University of Glasgow?

Among the various universities the authors represent, a few have had custom QMS software tool development, with some developed in-house, possibly through student artifacts developed, for example, in capstone projects. The tools used by some of the authors include:

1) QOBE system ${ }^{10}$,

2) CampusLabs $[11$, and

3) $\mathrm{CLOSO}^{12}$

One author has reported although there are excellent software accreditation-supporting solutions (such as CampusLabs, AEIFS, LIVETEXT, etc.), the cost of these can be prohibitively high (around \$200K+ USD).

Some of the authors' universities are certified under formal international quality standards (such as ISO 9001). For example, Sunway University, Malaysia is ISO 9001:2015 certified. The ISO 9001: 2015 framework allows the University to document and improve its practices, particularly programme delivery and research activities, to better satisfy the needs and expectations of its customers, stakeholders and interested parties. But the scope of ISO 9001 is typically understood by most of the authors to be complementary to more academically-focused quality efforts. The UK universities cater to the aforementioned Quality Assurance Agency (QAA)—UK's quality body for higher education. Similarly, Pakistan has established the Quality Assurance Agency through its Higher Education Commission (HEC).

\footnotetext{
https://www.ajman.ac.ae/en/about/planning-and-effectiveness/quality-assurance-manual

8 https://www.qaa.ac.uk/quality-code

"https://www.gla.ac.uk/media/Media_127773_smxx.pdf

"1thttps://qualityobe.com/

${ }_{11}^{11}$ https://www.campuslabs.com/

${ }_{12}^{12}$ https://www.smart-accredit.com/
} 
Some responses to questions relevant to this topic answered by the authors are reproduced below.

Question-How does your department/college/university solicit data from (please share the forms if possible) the alumni? the employers?

"Email correspondence. The University contacts the alumni and employers directly."

"Annual survey."

Question-Does your university have a software system to assist in outcome assessment?

"Excel sheets; however, we are transitioning to CampusLabs."

Question-List all direct and indirect assessment used by your department to evaluate Program Learning Outcomes/Student Outcomes. Provide a one-line description of each. Which body/entity (person or committee) is responsible for assessing the attainment of planned PLOs/SOs?

"Commonly use indirect assessment modalities include alumni survey, faculty survey, and exit survey."

"Direct Assessments: 1. Summative Data (curriculum-based) 2. Exit Exam Indirect Assessments: 1. Alumni Survey 2. Faculty Survey 3. Exit Survey 4. Formative Data (curriculum-based)"

"For direct assessments, PLOs/SOs are distributed among courses. The assessment structure (plan) for ABET is less exhaustive as it does not rely on all courses. Indirect assessments rely on course, second-year, and program exit surveys. These are conducted centrally by the QAA unit."

"Curriculum committee is responsible for program assessment and evaluation."

"ABET Steering Committee"

It is very common among the authors' universities to have a quality enhancement cell or similar directorate (e.g., other common names include Directorate of Institutional Planning and Effectiveness (IPE) or Academic Standards and Quality (ASQ) Department). It is common for such a department to be the point of interface with external accreditation organizations and to coordinate the development and dispatch of self-assessment reports.

\section{B. Continuous Quality Improvement (CQI)}

The word quality comes from the Latin word 'qualis' meaning of what kind. The quality of something can be said to be a part of its nature. At a high level, quality can be defined in any of the following ways:

1) Quality as fitness for purpose: A product or service exhibits quality as long as it can consistently meet the supplier's claims for it and the client's expectations. In other words, it must, as the British Standards Institution (BSI) defines quality, be "fit for purpose." This view of quality is sometimes called "quality in fact."

2) Quality as outcome assurance: A product or service is assumed to have quality when the producer has a quality system, sometimes called a quality assurance (QA) system, 
that supports the consistent production of the good or service to a particular standard or specification. (The presence of QA systems helps to ensure that the product or service is fit for purpose.)

3) Quality as excellence: A product or service is assumed to have quality if it can consistently "meet or exceed customer expectations."

4) Quality as transformation and striving for CQI: Excellence is an aspiration, a striving, which is demonstrated from the supplier's commitment to keep transforming for the better through a continuous quality improvement (CQI) process.

CQI refers to continuous deliberate efforts made based on feedback from stakeholders to bring about improvement in the effectiveness of the learning experience of students. It also means that "we systematically look ahead, considering 'where we want to be' and taking the necessary steps to ensure we get there. ${ }^{13}$

The authors have reported that faculty members are regularly provided training in person or through written documents for writing Course Learning Outcomes /Course Objectives as per Bloom's (or any other) taxonomy.

Most authors have reported that their institute requires a course assessment report to be submitted at the end of each course offering. Some authors have reported the use of the terminology "Instructor Course Assessment Report" (ICAR) while others reported the use of "Faculty Course Assessment Report" (FCAR).

Question-How is feedback/data provided by faculty members used to improve curriculum? Describe the process?

"The curriculum committee reviews the FCAR forms and the aggregate performance per SLO and recommends actions accordingly."

"Course report and file are reviewed by the program chair and possibly other members of the program, and decisions are made based on this."

"This is all done via Instructor Course Assessment Report (ICAR)."

Question-Are specific CQI processes developed? Describe some related process

"The faculty member and the curriculum committee at the program level are responsible for closing the loop."

Question-Do courses from all levels (or years) relied upon to measure PLOs/SOs? Or is there an alternate policy regarding what level of courses ought to be used for this purpose?

At one extreme, some authors noted "A subset of courses is chosen which covers all skills aspects covered through PIs."; on the other extreme, it was noted "Courses at all levels were used to measure SOs."

One author noted:

"The CLO/PLO assessments are reviewed at the end of each semester. Where failures take place in a certain CLO/PLO, decisions can range between course improvement

\footnotetext{
${ }^{13}$ Excerpt from https://www.gla.ac.uk/media/Media_127773_smxx.pdf
} 
(to take effect in the next instance), as well as remedial actions for follow up courses (for the same batch). The extent is dependent on the magnitude and distribution of the failure."

If an achievement criterion is not achieved, this raises a red flag that must be deliberated over by course instructor/coordinator to determine the reasons for the failure of cohort-level achievement attainment so that possible corrective measures may be taken.

When a cohort level failure on a CLO/PLO is observed, remedial actions are planned through consultation of the instructor with appropriate committees and coordinators. One author noted the following in response:

"A remedial action is recommended and implemented for the next assessment cycle. We are always pursuing enhancement in our program offerings. Even when the SLOs [PLOs] are satisfied, we raise the targets."

\section{Practices Related to Self-Assessment (or Self-Study) Report}

The self-assessment report (SAR) - also referred to in some jurisdictions such as ABET as selfstudy report (SSR) - is of varying length. In general, ABET reports have been reported to be shorter in page length (less than 100 pages) compared to those required by other agencies/boards which may exceed 300 pages (see Figure 9).

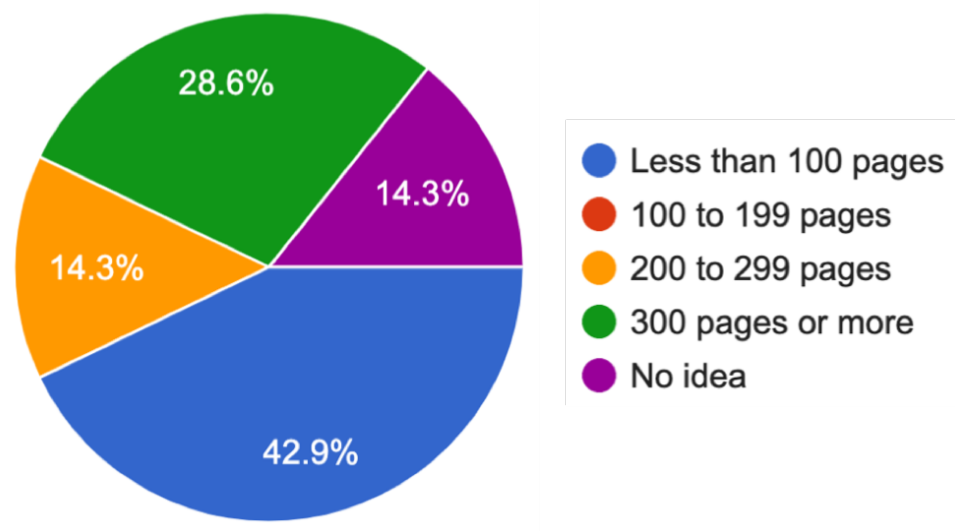

Figure 9: Average Length of the Self Assessment Report

The longer reports are some times elongated by additional material such as course outlines and faculty resumes, which can take up a lot of space for larger departments. ABET refers to the report created by the organization as a Self-Study Report (SSR), whereas it is common to refer to the same report by the name Self-Assessment Report (SAR) in some countries following Washington Accord. Templates for producing SSR provided by ABET are accessible from their website 14

As per the reported experience of the authors, the SAR/SSR is usually written by a committee involving representation from the QA department and led by a senior faculty member or department chairperson with contributions from many faculty members. $37.5 \%$ percent of the

\footnotetext{
${ }^{14}$ https://www.abet.org/accreditation/accreditation-criteria/self-study-templates/
} 
respondents reported having some non-faculty support staff for assisting in writing the SAR. A few authors have reported that their institute has bought software for assisting in accreditationrelated matters (including the self-assessment report). For the most part, the authors have reported semi-automated processes (e.g., using Microsoft Excel macros/formulaes or manual work).

\section{ON Assessment}

\section{A. Some Principles of Assessment}

"Effective assessment is more like a scrapbook of mementos and pictures than a single snapshot."-Jay McTighe.

1) Student learning is cumulative over time: It is important to keep in mind that student learning is cumulative and what students learn in one course is used and leveraged in subsequent courses. It is thus important during assessment to keep in mind the cumulative effect of student learning and not be myopic when interpreting results. This is particularly the case during the early phase of student's education. It is equally important to realize that the graduate attributes (or PLOs or SOs) as defined are expected to be attained or achieve by graduation time. In light of this, it becomes important to think about when and from whom to collect data. Assessments taken early on during the program may therefore be considered formative (and used to customize instruction) so that the evaluation can help improve areas of learning before the end of the program/course.

2) One cannot do everything all the time: As per ABET official training (see Figure 10] [26], it is stated that one cannot do everything all the time and that it is important to prioritize focus on high-level indicators of outcome achievement.

\section{B. Types of Assessment}

Broadly speaking, assessment techniques can be either summative or formative. In summative assessment, the purpose is to assess learning-i.e., how well a student is performing at a specific point in time. Examples of summative assessment are end-term exams, mid-term exams, and standardized state tests that quantitatively measures the current level of learning of a student. Summative assessment is also called "assessment of learning" - to be contrasted with "assessment for learning", which is the domain of formative assessment. The purpose of formative assessment is to principally utilize the information gained through the assessment to guide changes in the instructional and curriculum methodology, in ways that would not be possible without this feedback, for the explicit aim of improving the student's learning. The use of assessment information is key to the idea: To be considered formative, assessment evidence must be acted upon to inform subsequent instruction.

Assessment can also be categorized as direct assessment (where the student demonstrates learning) vs. indirect assessment (where the student describes learning, e.g., through self-reports). In our survey, some authors have reported the use of indirect assessments for PLO while others rely on exit surveys conducted when a course concludes, the second year of studies (half-way mark in a 4-year degree), and at graduation. In terms of logistics, this may be centrally managed by a university- or college-level QEC/QAA unit.

Some responses to questions relevant to this topic answered by the authors are reproduced below. 


\begin{tabular}{|c|l|}
\hline \multicolumn{1}{|c|}{ Course Assessment } & \multicolumn{1}{c|}{ Program Assessment } \\
\hline $\begin{array}{l}\text { - Cannot "cover" all Topics } \\
\text { related to Subject }\end{array}$ & $\begin{array}{l}\text { Cannot "cover" all Outcomes related } \\
\text { to Program Educational Objectives }\end{array}$ \\
\hline $\begin{array}{l}\text { - Cannot "cover" all Concepts } \\
\text { related to each Topic }\end{array}$ & $\begin{array}{l}\text { Cannot "include" all Performance } \\
\text { Indicators related to each Outcome }\end{array}$ \\
\hline $\begin{array}{l}\text { - Decisions made based on } \\
\text { context of course and } \\
\text { characteristics of students }\end{array}$ & $\begin{array}{l}\text { Decisions made based on context of } \\
\text { your program and characteristics of } \\
\text { students }\end{array}$ \\
\hline $\begin{array}{l}\text { - Not all Concepts are at the } \\
\text { same performance (cognitive) } \\
\text { level }\end{array}$ & $\begin{array}{l}\text { Not all Performance Indicators are at } \\
\text { the same expectation (cognitive) } \\
\text { level }\end{array}$ \\
\hline $\begin{array}{l}\text { - Assessment data taken at the } \\
\text { Concept level }\end{array}$ & $\begin{array}{l}\text { Assessment data taken at the } \\
\text { Performance Indicator level }\end{array}$ \\
\hline $\begin{array}{l}\text { Assumptions related to } \\
\text { performance on Topics based } \\
\text { on performance on Concepts }\end{array}$ & $\begin{array}{l}\text { Assumptions related to performance } \\
\text { on Student Outcomes based on } \\
\text { demonstration of Performance } \\
\text { Indicators }\end{array}$ \\
\hline
\end{tabular}

Figure 10: An analogy of course vs. program assessment is illustrated (Credit: [24]). Some pragmatic concerns are reflected such as the need to be judicious and pragmatic in outcome assessment (since "covering" all topics [outcomes], concepts [PIs] for all students may be impractical).

Question-Are any indirect assessments performed for the CLO/PLO assessment? Describe some common modes.

"ABET does not like to see indirect measurements. It is ok to utilize indirect measurements along with direct measurements but not alone."

"Yes. Indirect assessments rely on course, second-year, and program exit surveys. These are conducted centrally by the QAA unit."

"1. Alumni Survey 2. Faculty Survey 3. Exit Survey 4. Formative Data (curriculumbased)."

Question-Are any subjective/qualitative assessments performed for the CLO/PLO assessment? Describe some common modes.

One author, also an ABET PEV, noted:

"ABET requires assessment to be measurable. No subjectivity to the extent possible."

"Final examination, and coursework (e.g., individual and group projects, presentations, debates, tests, lab experimentation, posters, reflection papers, and proposal of business plans)." 


\section{Cohort-Level Assessment vs. Per-Student Assessment}

Most authors have reported that CLOs are not tracked per student but at the cohort level. Such practice is often made to keep the accreditation-linked workload manageable so that the workload does not impinge upon the other duties of faculty members such as research. The course evaluation form filled by the course instructors is part of this course portfolio (folder). We reproduce a typical comment received from an author:

"it should be noted that a thorough, per-student tracking of CLO/PLO attainment is not commonly exercised at our University."

Program Assessment is not about individual student assessment. In fact, when the cohort is very large, even sampling of the cohort (let's say sampling 50\% of the cohort) may be justified. The majority of the authors have reported that it is common to focus on per-cohort assessment (whether exhaustively or through sampling) rather than on per-student assessment.

Some responses to questions relevant to this topic answered by the authors are reproduced below.

Question-Is the Course Learning Outcome (CLO) assessment performed for each student or a sample of students?

"For each student and then rolled up to the course level."

"CLO assessments involve all students."

"A sample of students."

Question-How is it determined that an entire class has cleared a PLO assessment?

"A comparison between the aggregate average of the cohort and a target number."

"Based on the percentage of students in each thresholds. $70 \%$ of students must either meet or surpass the expectation to consider the CLO/PLO/SO attained."

Question-How is it determined that a student has cleared a PLO assessment?

"That's not as important; however, it can be achieved through a comparison between the student's average and a target number."

"If the student falls in top 2 categories (Developed, Exemplary)."

Question-Is the assessment for the Program Learning Outcomes (PLO), or Student Outcomes (SO), performed for each student or for a sample of students of the entire program?

CLO feeding into PLO assessment:

"PLO assessment is based on the overall score of students in each CLO that is mapped to that PLO."

"This was done for all students collectively and not for individual students."

"A sample of students."

"Entire program." 
More than one author noted "Each student."

\section{Frequency and Timing of Assessment}

Some boards allow for long-term accreditation (e.g., ABET allows accreditation of up to 6 years), which will cover multiple batches of the program. It is also common for some agencies to accredit separately per batch. This also depends on the maturity of the program and the stability and quality of the processes. Diversity in the frequency of accreditation visits was reported by the authors (see Figure 11).

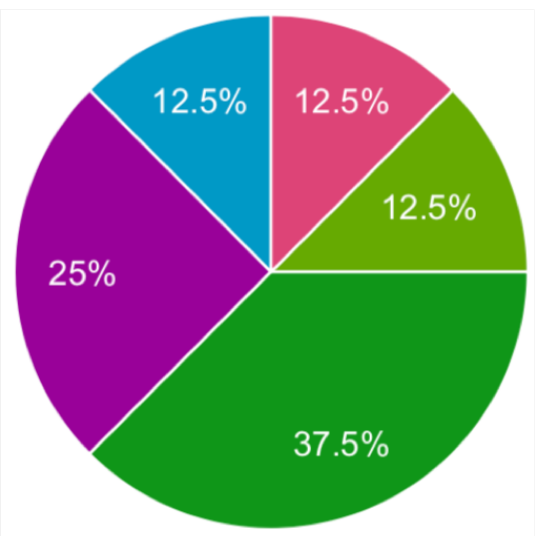

Yearly

Once in Two Years

Once in Three Years

Once in Four Years

Once in Five Years

Depends on visit outcome

Once in 6 years

Once is Six years.

Figure 11: Average Frequency of Accreditation Visits

Some responses to questions relevant to this topic answered by the authors are reproduced below.

Question-Are the Program Learning Outcomes (PLOs) evaluated and assessed for a batch/student only once at the end of the program or is the assessment performed regularly? What is the frequency of the PLO assessment (per semester; annually; bi-annually; or once at the end)?

"Different PLOS/SOs are assessed at different times in a cohort's progress. Only every third cohort is tracked. Assessments are distributed on fall and spring. Summer courses are not included in assessment, except for the internship requirement."

"The assessment is generally done once in two years."

"A sample of students. Frequency is per semester."

"For a cohort; we assess 2-3 SLOs every year."

Question-Are only advanced-level courses considered for the purpose of outcome assessment or are the earlier courses (1st and 2nd year) considered?

"They used to be. Now we only rely on summative experiences in calculating assessments for the program. This is done every three years. However, non-summative experiences are used for formative assessments, and may facilitate remedial actions for an ongoing cohort."

"All levels are considered. Of course, higher level courses are more important. However, low level classes also provide good insight into the lower courses." 
"Generally advanced level courses are considered for PLOs assessment while making sure that all skills and PIs are covered."

"Courses at all levels were considered. However only formative data was collected from 1st year courses."

"All courses are considered, including first and second years."

\section{E. Assessment of Program-Level Outcomes}

PLOs can be assessed either directly or indirectly. For direct assessment, the extent of attainment of PLOs can be determined in at least two different ways. Firstly, CLOs-based assessment, where the attainment of the Course Learning Outcomes (CLOs) is used to define the degree of PLOs achievement. Secondly, rubrics-based assessment, where each PLO is represented in terms of some Performance Indicators (PIs), which are then assessed through well-defined rubrics to measurement the PLO attainment.

Some responses to a relevant question provided by the authors are reproduced below.

Question-Do OBE assessment segregate students into predefined categories? Is this segregation based on number marks out of the total or a rubrics-based approach is taken?

"The attainment thresholds are as follows. < 60: does not meet expectations; 60-70: progressing toward expectations; 70-90: meets expectation; 90-100: exceeds expectations."

"Yes; we separate then into Excellent, Average, Minimal, Unacceptable (EAMU) groups."

One author has reported that

"the target performance level has been set to $70 \%$ by the Department. The attainment level is the percentage of students that falls in the Developed and Exemplary categories. There are four categories: Poor (non-existent), Developing, Developed, and Exemplary."

Another author has noted that their department follows the following guidelines:

"less than $60 \%$ (does not meet expectations); 60-70 (progressing toward expectations); 70-90 (meets expectation); and 90-100 (exceeds expectations). 70\% of students must be either meet expectation or above to consider the CLO/PLO/SO attained."

Some responses to questions relevant to this topic answered by the authors are reproduced below.

Question-How are qualitative outcomes (such as the ability to act ethically; the ability to communicate; the ability to work in teams; the ability to solve complex engineering problems) measured?

"The FCAR report allows the faculty to present their qualitative feedback on a given course."

"They are generally measured via Rubrics and PIs." 


\section{F. Course-Level Assessment}

Course-level assessment is performed by evaluating the student's performance on the pre-defined CLOs. The CLO information typically feeds into PLO/SO assessment and is considered. PLO/SO can also be assessed through rubrics but CLOs-based assessment has the advantage that it provides the instructors with useful feedback about students' learning in the specific courses and it can deliver valuable information about the strengths and weaknesses at the course-level.

Some responses to questions relevant to this topic answered by the authors are reproduced below.

Question-How is it determined that a student has cleared a CLO assessment?

"If the student falls in top 2 categories, (Developed or Exemplary) then it is assumed that student has cleared this assessment."

"Scoring $70 \%$ in the CLO is considered as attaining the CLO"

"Target level attainment."

"It's not determined."

Authors were asked if their institute ensures that the assessments cover all the CLOs? Most reported that this is done indirectly through their course assessment report where assessment distribution is documented. Some authors also reported that they have instituted procedures where each CLO is assessed at least twice in a semester. One author noted: "The focus of continuous improvement cycle at this (course) level is the evaluation and attainment of Course Learning Outcomes. At the end of the term, each course coordinator assesses the attainment of Course Learning Outcomes for the course. In addition, the course coordinator is responsible for writing/assembling recommendations in the "Course Evaluation Form" that is attached with the course portfolio (folder). One author reported that in their university, the course coordinator at the end of each term submits a "Course Portfolio" to the Curriculum Committee for deliberation and for archiving. This course portfolio is used for CLO assessment at the cohort level.

\section{G. The Use of Rubrics}

Rubrics serve as a useful tool for defining a common "language" to help faculty and students talk about expected learning. Rubrics clearly define what is expected of students in order to achieve a particular level of performance or learning outcome and can facilitate learning since it provides the assessed students with clear information about how well they have performed and what they need to accomplish to further improve their performance. Well-defined rubrics also serve a role in providing uniformity in grading when multiple assessors are involved. Rubrics are a useful tool for the direct assessment of PLOs/SOs or indirect assessment (done through PIs). Rubrics are useful explicitly stating the expectations for students' performance for each learning outcome or performance indicator.

Some responses to questions relevant to this topic answered by the authors are reproduced below.

Question-Describe the cases and purposes for which your department/college/university uses rubrics? Does your department/college/university use rubrics for assessing the attainment of 
CLOs? Does your department/college/university use rubrics for assessing the attainment of PLOs?

"An overall, high-level rubric has been developed for each of the ABET SOs. This rubric is meant to be instructive for the professor or TA overseeing the assessment, and can be used (together with the description of the SO) to guide the derivation of further, targeted rubrics, as well as basis for answer keys and question design."

"Rubrics are used to assess various attributes. As an example of creativity, the outcome to be measures is the ability to generate new, unique, original, outstanding creations and designs. The assessment task can be creative projects and products."

"The rubrics are used for almost all assessments however detailed assessments rubrics are used for final year project report and presentation. Also projects involving teams use rubrics."

"We use it for capstone projects, theses, dissertations, and course level attainment."

\section{H. Assessing Attainment of Program Education Objectives (PEOs)}

Some responses to questions relevant to this topic answered by the authors are reproduced below.

Question-How are the Program Education Objectives (the long-term objectives of an education program that are expected to be demonstrated within a few years of graduation) assessed?

"They are assessed by 1) closing the loop action plan (including items) from previous cycle, 2) alumni survey, 3) faculty survey, 4) employer survey, and 5) external advisory committee."

"The University gathers feedback from alumni and employers. The feedback shows that graduates are appreciated by employers, and career opportunities for graduates look positive in the near future. The University has an Alumni office who handles this."

One author who is also an ABET Program Evaluator (PEV) noted "They do not have to be assessed as per ABET requirements. However, alumni survey can be utilized for this purpose."

"Keep in mind that ABET ${ }^{15}$ does not expect all graduates to attain all Program Educational Objectives."

"PEOs are indirectly assessed via the attainment of PLOs."

"Achievement of the PLOs/SO enable the attainment of the PEOs.."

\section{Relationship of Grades and Outcomes}

It is also important to note that $\mathrm{OBE}$ systems, in recent times, have realized for a need for outcome assessment to move away from a quantitative approach relying on grades and marks to a more qualitative approach that aims to describe the quality of what the student knows and what they can do. In the words of Gloria Rogers, Senior Adjunct Director for Professional Offerings

${ }^{15} \mathrm{ABET}$ no longer requires assessment of attainment of Program Educational Objectives: https://www.abet.org/ changes-to-the-accreditation-criteria-general-criterion-2-program-educational-objectives/ 
at ABET, and Vice President Institutional Research, Planning, and Assessment at Rose-Hulman Institute of Technology,

"In outcomes assessment at the program level, the primary question that needs to be answered is, "Can students demonstrate the ability to perform at an acceptable level in each of the program outcomes?" Program assessment focuses on providing evidence that students can demonstrate knowledge or skill directly linked to specific program outcomes. Grades per se do not provide that information. [...] Grades have limited use for program assessment as they do not have diagnostic value. Grades can be a 'flag,' but do not point to specific strengths and weaknesses of what students know or can do." [27]

Some responses to questions relevant to this topic answered by the authors are reproduced below.

Question-Do you see any relationship between letter grades and attained of CLOs or PLOs/SOs? Is it possible for a student to have low grade and still attain all CLOs or vice-versa.

"No; grades should not be used as an assessment tool as they cannot be mapped to a specific CLO and SLO."

"We struggled with this question. However we kept these two as separate issues."

"Assessments may not be correlated with grades."

\section{J. Formative Assessment}

Formative assessment and summative assessment do not have a unique definition in theory or practice [28]. In this paper, we adopt the definition offered by Black and Wiliam [28] that formative assessment encompasses "all those activities undertaken by teachers and/or by students which provide information to be used as feedback to modify the teaching and learning activities in which they engage" .

The use of formative assessment is not as widespread as is desirable. Some authors have reported that formative assessment is often considered as an extra burden and not used frequentlydespite its documented benefits, particularly for the weaker students. In some cases, formative assessments are made to track student's and cohort's progress but the feedback is unfortunately not shared with the students-which dampens and dilutes the purpose of formative assessment. We feel that broader awareness of frameworks for formative assessment such as Assessment For Learning (A4L) and the related research would be helpful in promoting learning (particularly for weak students).

Faculty typically provide formative feedback in the form of feedback on marked student work or through rubrics. Based on the rubrics, general and specific feedback is provided to students. For instance, students from a group are informed about the lack of certain aspects in the Literature Review section of their project report so that they can revise based on the feedback. One common approach is defined as follows: "The purpose of Formative Assessment, carried out during the initial years of a program, is to assess the ongoing performance activities and obtain feedback for improvement of relevant processes and teaching and learning methodologies. On the other hand, Summative Assessment is carried out at or near the conclusion of a program in order 
to determine the extent to which PLOs have been attained." [Source: https://www.ajman.ac.ae/ upload/docs/Quality_Assurance_Manual1.pdf].

There is varying practice-some universities mandate the sharing of a solution/mark scheme to their assignments/exams but at other places, it is optional and marking schemes are provided in a responsible manner to prevent from spoon-feeding. Nevertheless, feedback/ guidance, or solution/ marking scheme to similar questions, is provided to students instead to seek for the solution.

Some responses to questions relevant to this topic answered by the authors are reproduced below.

Question-Is it necessary for the faculty members to provide a solution/mark scheme to their assignments/exams or optional?

"It is always better to provide rubrics."

"yes. this was a strict requirement."

"Optional. Solutions or marking schemes are provided in a responsible manner to prevent from spoon-feeding."

Question-What are the strategies to achieve SLOs using formative feedback?

"Formative feedback is a nice to have but it is not necessary for accreditation. Assessment does not have to include formative feedback to the students."

Question-How do instructors generate formative feedback about the performance of students? Share your own experiences and your knowledge about other instructors' practice in terms of how formative feedback is provided.

"Formative feedback was generally provided based on instructor's opinion/perception of students/class. Since we were doing evaluation for the whole batch and not individual student, this approach worked OK."

"It takes the form of feedback on marked student work, and does not involve measurement of specific assessments."

"Comments on exams, homeworks, etc. Also, Canvas and other LMS can be used for that purpose."

Question-Do the faculty members in your department/university use the term "formative feedback" during their instruction or accreditation-related documentation?

Most reported yes; a few noted no.

VI. Insights Learned, Best Practices, and Common Pitfalls

A. Handling Accreditation Visits

Handling accreditation visits can be unsettling. In this regard, most boards make available helpful suggestions-e.g., ABET has a lot of documentation online ${ }^{16}$. In this section, we share some

\footnotetext{
${ }^{16}$ https://www.abet.org/accreditation/get-accredited/accreditation-step-by-step/
} 
tips the authors have shared from their own experiences.

Some responses to questions relevant to this topic answered by the authors are reproduced below.

Question-Any learning experiences from handling accreditation visits that you'd like to share?

"It is good to go through a mock visit before the actual visit. Make sure that all assessment material, senior design project artifacts, and demos ready.

"Make sure to know the difference between PEOs and SLOs. Do not miss any of the constituent groups while reviewing the PEOs."

"Accompany findings with an Executive Summary."

"In our case, the most important experience was to understand requirements of accreditation bodies (from your curriculum) and make sure that these are met before embarking upon the journey of accreditation. Make sure that the program requirements are met as defined by the respective accreditation agency.."

"Good documents especially managing neat and clean course folders that are neatly arranged is important."

Question-Apart from SAR, what kind of evidence is expected by PEVs during their assessment visits?

- "Assessment principles, methods and practices are aligned with SLO, PLO."

- "Mechanisms to ensure validity, validity, reliability, consistency, and currency are in place. It should be ensured that each topic/CLO is assessed in at least two different assessments."

- "Results are communicated to students within reasonable time."

- " "Grading, assessment and appeal systems must be publicized."

- " "Process by which security of assessment documents and records are assured."

- $\quad$ "Assessment data, senior design artifacts, meeting minutes, meetings with students and advisory board members."

- " "Rubric should be provided for all assignments."

\section{B. How to Self-Assess?}

One can self-assess the quality of their accreditation program and in particular the continuous quality improvement (CQI) procedures of their institute by ensuring ... "(1) Sustained partnerships with stakeholders are developed; (2) Objectives (PEOs) are periodically evaluated for continued relevancy; (3) Outcomes are defined by a manageable number of measurable performance indicators (PIs); (4) Where necessary, educational practices are modified based on evaluation of assessment data; (5) When needed, assessment methods are modified based on evaluation processes; and that (6) Evaluation leads to decision making/ action" [27].

\section{Developing the Strategic Vision}

Some pointers are presented next relating to the institute's and program's strategic vision: 
- There is a need to fully incorporate the student as an important stakeholder in the OBE system and to commit to the principle of student engagement in quality matters at all levels.

- Students must be given training and the related information is disseminated widely-e.g., the program structure and the intended outcomes should be visible for students in the handbook and school's/university's website and the regular communication/explanation of CLOs to students is critical for the successful attainment of outcomes.

- Apart from this, the students should be encouraged and trained to reflect on their learning experience and to self-assess and track their progress to make them proficient on independent lifelong learning.

\section{Establishing CQI system}

To be successful in OBE accreditation, it is essential that "the program uses a documented process incorporating relevant data to regularly assess its student outcomes, and to evaluate the extent to which they are being met. The results of these evaluations of student outcomes must be used to effect continuous improvement of the program through a documented plan."

Some responses to questions relevant to this topic answered by the authors are reproduced below.

Question-What evidence should be presented to demonstrate CQI system being in place "Course, and programme monitoring reports. Periodic programme reviews are conducted in the University."

"Assessment data, meeting minutes."

Question-Experiences in developing and/or executing an assessment infrastructure.

"Assessment should be planned at the beginning of the semester to ensure that the right assessments are selected to assess students in order to achieve the learning outcomes."

"Utilizing a software solution like CampusLabs helps a lot."

Question-Any advice on what steps program managers can take to avoid accreditation failures or adverse observations?

"Students are unaware that student interview session is not the right channel for complaint. Students should provide both good and bad practices in the Department instead. Program leaders should provide briefings to students before the student interview session."

"Start early and track the collection of assessment data and evaluation reports."

\section{E. Experiences with Training}

Some responses to questions relevant to this topic answered by the authors are reproduced below.

Question-Experiences with training and simplifying assessment and accreditation language and procedures to faculty. 
- "Faculty should be familiar with the accreditation terminology and the assessment processes within the institution. It is a good idea to utilize the departmental meeting to train the faculty indirectly."

- "OBE trainings are provided to staff from time to time. So, there is no issue with accreditation language. Most staff are well versed with common OBE language such as PLO, PEO, PA, Bloom's taxonomy, and so on."

\section{F. Engaging Faculty and Getting Them To Buy Into OBE}

The authors noted that an active OBE implementation requires buy-in from the faculty and particularly from the highest authorities. The overall reception of accreditation process was mixed with numerous authors noting that it is common for some faculty members to find accreditation processes as stifling and like a chore-particularly when the accreditation system has been freshly instituted. This is consistent with the reported literature. Insights from experienced educators on change management [29, 30] can be useful for managing the change with minimal friction. Froyd describes that Kotter's change approach [31] provides a particularly robust model for curriculum change within engineering departments because it "focuses on a process of building a coalition around a recognised need rather than efforts of individual faculty and/or the sufficiency of research data" [30].

Some responses to a relevant question provided by the authors are reproduced below.

Question-Experiences and insights in engaging faculty, administration and students in assessment or accreditation.

- "Buy-in from both faculty and administrators is key, but is hard to achieve, especially where there are no apparent consequences to participate or not."

- "This is a hard task. Most faculty members feel that this is too time consuming. Very few realize the impact on quality. And administration at times put too much load on faculty members involved in such activities."

- "It is important to engage all constituents that are identified in the self-study report. Do not miss any of the constituent groups."

- "Better communication and explanation/clarification of CLOs to students is very critical in the success and attainment of outcomes."

\section{G. General Insights}

With the Washington Accord mandating OBE, and with most national accreditation organization in tow, implementing OBE is a must and therefore resistance to it has largely watered down. Nonetheless, implementing a genuine OBE requires an enthusiastic senior faculty member who can champion OBE and impress upon the faculty members the need to implement it in letter and spirit.

Quality procedures should not be merely treated as necessary props for accreditation. Quality procedures should instead be the basis for management and progress. In the case where accreditation becomes the summum bonum of quality management efforts, the real objectives of accreditation can be compromised as faculty members will figure out short cuts (similar to how students fail to learn optimally when they learn according to the test). Eventually, the 
accreditation culture has to become from ad-hoc, personality-driven, and accreditation-driven to one that is structurally-driven and focused on improvement and validation.

Some general tips follow:

- More data are not always better.

- Do not let perfection stand in the way of progress.

- Address faculty concerns (e.g., by reducing the workload and burden of the massive data collection processes; increase confidence in the process by justifying how the processes will improve the standard of education).

- Move from a focus on individual courses to the cumulative effect of learning at the program level.

\section{H. Common Pitfalls and Caveats}

1) Managing Faculty Burden: It was noted by some authors that there is a need to find the right balance towards ensuring that the faculty members are not unduly restricted with the unnecessary burden for documentation since faculty members often have considerable and varied obligations.

In terms of the faculty's involvement in accreditation related matters, at one level all the faculty members are involved - as is necessary in every quality assurance undertaking - but the accreditation-related workload is different for different faculty members and it is typical for a university to have dedicated committee members to oversee the implementation of accreditationrelated matters. The burden increases considerably when an accreditation visit is due or when there is a deadline to submit the self-study (or self-assessment) report.

"Quality and accreditation is important, but so is faculty time - who often have considerable and varied obligations, e.g. in research-based universities with populated masters and doctoral programs."

Some responses to questions relevant to this topic answered by the authors are reproduced below.

Question-How many people in your department (in percentage terms) are involved in accreditationrelated administrative matters? How many of these people are directly and actively involved? (What percentage of their time are they actively contributing)

The authors reported a wide range: from $5 \%$ of faculty members (working almost $70 \%$ of their time on accreditation) to all of the faculty. Most however reported in the range of 10 to $20 \%$.

Question-What is the overall reception of accreditation in your department among regular and adjunct faculty members? Do they perceive this as a contributor to better student learning outcomes or do they see this as a chore and a hassle? If there is a split, provide approximate figures on the relative proportions.

"I think almost $30 \%$ believe this is good. And $70 \%$ would say that this is unnecessary. At times this feels like a rat race amongst universities for ranking and prestige." 
"Well received; I believe that all faculty value the benefits of accreditation to the institution and its program offerings."

"Chore and a hassle, unfortunately."

Question-Any comments on the potential caveats of the accreditation process (such as the tendency to fudge data; the tendency to rely excessively on quantitative metrics rather than on qualitative judgments; the excessive burden of documentation needed for accreditation)?

"Absolutely, as an ABET PEV and consultant, I noticed some programs tend to fudge the data. Such programs are typically after the accreditation itself and do not care about the benefits that the accreditation process can generate. I noticed that such cases are primarily outside the US."

Question-Do you think that accreditation has resulted in improving the quality of the educational programs? Any comments on the side effects of the process?

"The quality of the educational program has improved many folds. In our case, it was not very well planned because of lack of expertise and hence the process was painful because of lack of direction. In later years, this pain point has also disappeared since we now have experienced faculty members in this area."

"Yes. Generally, it's necessary to ensure programmes are conducted as planned as in the syllabus."

"Yes. The side effect is that it sometimes makes the overall process of teaching too methodical with a lot of unnecessary limitations put on the instructors."

2) Common Mistakes Observed: Some common mistakes reported by the authors, some of whom have worked as PEVs, are documented next.

- "Both teaching staff and students appear to be unfamiliar with the OBE approach to education."

- "PLOs are irrelevant to the programme being evaluated and the University mission."

- "Relationships between different programmes offered by the Department are unclear."

- "Some of the elective courses are not offered although they have been listed."

- "The effects to PLOs are unclear."

- "Some skills such as research are not incorporated into PLOs. Hence, programmes are not producing research-ready graduates. There is lack of student progression to Master's and PhD levels."

- "The consistency in the practice of OBE in the syllabus should be improved."

- "Assessment methods and their allocations should be consistently presented in syllabus."

- "Procedures to evaluate and analyze the assessment outcomes and the effectiveness of assessment (e.g., in achieving the PEOs) can be designed and applied across the University."

- "Lack of hardware and software facilities in the lab."

Issues with CQI can include: (1) process is not adequately documented; (2) immature process and/or plan not implemented; (3) sustainability of the process is in question because of the 
complexity or the growth of the program.

Some responses to a relevant question provided by the authors are reproduced below.

Question-In your experience, what are some of the common mistakes people make in accreditation?

"Confusing the PEOs with the SLOs and writing them similarly without making sure that the first reflects what the students are supposed to achieve few years after graduation while the second reflects what the students should achieve by the time of graduation."

\section{CONCLUSIONS}

In this paper, the authors (a geographically dispersed set of academics working in nine different countries: namely, Pakistan, United Kingdom, United Arab Emirates, United States of America, Saudi Arabia, Singapore, Qatar, China, and Malaysia) have presented a global international perspective on OBE accreditation standards, practices, and attitudes. We have shared perspectives and a description of international practice in the areas of developing strategic vision, quality management, assessment, and continuous quality improvement. We present a synthesis of the major insights learned through our survey and also list some common pitfalls. The authors generally agree that the accreditation processes have improved the quality of educational programs and has resulted in better quality of education - particularly for weaker students - and has resulted in the reduction of variation in quality that can arise from unregulated and unsupervised teaching in which the quality is dependent largely on the instructor with the system playing no major role.

\section{REFERENCES}

[1] W. G. Spady, Outcome-Based Education: Critical Issues and Answers. ERIC, 1994.

[2] J. E. Froyd, P. C. Wankat, and K. A. Smith, "Five major shifts in 100 years of engineering education," Proceedings of the IEEE, vol. 100, no. Special Centennial Issue, pp. 1344-1360, 2012.

[3] H. Chowdhury, F. Alam, S. K. Biswas, M. T. Islam, and A. S. Islam, "Quality assurance and accreditation of engineering education in bangladesh," Procedia Engineering, vol. 56, pp. 864-869, 2013.

[4] S. M. Said, C.-O. Chow, N. Mokhtar, R. Ramli, T. M. Y. S. T. Ya, and M. F. M. Sabri, "Accreditation of engineering programs: an evaluation of current practices in malaysia," International Journal of Technology and Design Education, vol. 23, no. 2, pp. 313-328, 2013.

[5] W. Lixun, "Designing and implementing outcome-based learning in a linguistics course: a case study in hong kong," Procedia-Social and Behavioral Sciences, vol. 12, pp. 9-18, 2011.

[6] G. Prasad and C. Bhar, "Accreditation system for technical education programmes in india: A critical review," European Journal of Engineering Education, vol. 35, no. 2, pp. 187-213, 2010. 
[7] A. Shafi, S. Saeed, Y. A. Bamarouf, S. Z. Iqbal, N. Min-Allah, and M. A. Alqahtani, "Student outcomes assessment methodology for ABET accreditation: A case study of computer science and computer information systems programs," IEEE Access, 2019.

[8] A. A. Rabaa'i, A. R. Rababaah, and S. A. Al-Maati, "Comprehensive guidelines for ABET accreditation of a computer science program: the case of the american university of kuwait," International Journal of Teaching and Case Studies, vol. 8, no. 2-3, pp. 151-191, 2017.

[9] K. Mahmood, K. M. Khan, K. S. Khan, and S. Kiani, "Implementation of outcome based education in Pakistan: A step towards washington accord," in 2015 IEEE 7th international conference on engineering education (ICEED). IEEE, 2015, pp. 166-170.

[10] S. R. Naqvi, T. Akram, S. A. Haider, W. Khan, M. Kamran, N. Muhammad, and N. Nawaz Qadri, "Learning outcomes and assessment methodology: Case study of an undergraduate engineering project," The International Journal of Electrical Engineering \& Education, vol. 56, no. 2, pp. 140-162, 2019.

[11] R. C. Castillo, "A paradigm shift to outcomes-based higher education: policies, principles and preparations," International Journal of Sciences: Basic and Applied Research, vol. 14, no. 1, pp. 174-186, 2014.

[12] J. Engelbrecht and A. Harding, "The impact of the transition to outcomes-based teaching on university preparedness in mathematics in south africa," Mathematics Education Research Journal, vol. 20, no. 2, pp. 57-70, 2008.

[13] I. Akduman, L. Özkale, and E. Ekinci, "Accreditation in Turkish universities," European Journal of Engineering Education, vol. 26, no. 3, pp. 231-239, 2001.

[14] Q. Memon and A. Harb, "Developing electrical engineering education program assessment process at UAE university," Australasian Journal of Engineering Education, vol. 15, no. 3, pp. 155-164, 2009.

[15] A. Anwar and D. Richards, "Is the USA set to dominate accreditation of engineering education and professional qualifications?" in Proceedings of the institution of civil engineers-civil engineering, vol. 166. Thomas Telford Ltd, 2013, pp. 42-48.

[16] L. Schachterle, "Outcomes assessment at WPI: A pilot accreditation visit under engineering criteria 2000," Journal of Engineering Education, vol. 87, no. 2, pp. 115-120, 1998.

[17] M. H. Davis, Z. Amin, J. P. Grande, A. E. O’Neill, W. Pawlina, T. R. Viggiano, and R. Zuberi, "Case studies in outcome-based education," Medical teacher, vol. 29, no. 7, pp. 717-722, 2007.

[18] ABET, "Accreditation definitions," 2020, accessed on: 1-Feb2020. [Online]. Available: https://www.abet.org/accreditation/accreditation-criteria/ criteria-for-accrediting-engineering-programs-2019-2020/\#definitions

[19] S. R. Covey, The 7 Habits of Highly Effective People: Powerful Lessons in Personal Change. New York: Free Press, 2004.

[20] M. Carter, R. Brent, and S. Rajala, "EC 2000 Criterion 2: A procedure for creating, assessing, and documenting program educational objectives," in American Society for Engineering Education (ASEE) Annual Conference \& Exposition, 2001. 
[21] E. Council, "The accreditation of higher education programmes," 2014, accessed on: 1-Feb-2020. [Online]. Available: https://tinyurl.com/yxpkopvs

[22] G. Wiggins and J. McTighe, Understanding by design. ASCD, 2005.

[23] J. Biggs, "Enhancing teaching through constructive alignment," Higher education, vol. 32, no. 3, pp. 347-364, 1996.

[24] ABET, "Institute for the development of excellence in assessment leadership (IDEAL) presentation," 2016, accessed on: 1-Feb-2020. [Online]. Available: https://tinyurl.com/ ABETIDEAL

[25] R. M. Felder and R. Brent, "Designing and teaching courses to satisfy the ABET engineering criteria," Journal of Engineering Education, vol. 92, no. 1, pp. 7-25, 2003.

[26] G. Rogers, "ABET fall 2010 webinar on Defining Student Outcomes," 2010, accessed on: 1-Feb-2020. [Online]. Available: https://tinyurl.com/GloriaRogersABETWebinar

[27] —_, "Assessment planning flowchart," 2003, accessed on: 1-Feb-2020. [Online]. Available: https://tinyurl.com/GRogersAssessmentFlowChart

[28] P. Black and D. Wiliam, "Assessment and classroom learning," Assessment in Education: principles, policy \& practice, vol. 5, no. 1, pp. 7-74, 1998.

[29] D. E. Goldberg and M. Somerville, "A whole new engineer," The coming revolution in Engineering Education. Douglas MI: Threejoy, 2014.

[30] J. Froyd, D. Penberthy, and K. Watson, "Good educational experiments are not necessarily good change processes," in 30th Annual Frontiers in Education Conference. Building on A Century of Progress in Engineering Education. Conference Proceedings (IEEE Cat. No. 00CH37135), vol. 1. IEEE, 2000, pp. F1G-1.

[31] J. P. Kotter, Leading change. Harvard Business Press, 2012. 